\title{
Matrix-Dependent Local Retention of Secretory Vesicle Cargo in Cortical Neurons
}

\author{
Joris de Wit, Ruud F. Toonen, and Matthijs Verhage \\ Department of Functional Genomics, Center for Neurogenomics and Cognitive Research, Vrije Universiteit Amsterdam (VUA) and VUA Medical Center, \\ 1081 HV Amsterdam, The Netherlands
}

\begin{abstract}
Neurons secrete many diffusible signals from synaptic and other secretory vesicles. We characterized secretion of guidance cues, neuropeptides, neurotrophins, and proteases from single secretory vesicles using pHluorin-tagged cargo in cortical neurons. Stimulation triggered transient and persistent fusion events. Transient events represented full release followed by cargo diffusion or incomplete release followed by vesicle retrieval, as previously observed in neuroendocrine cells. Unexpectedly, we also observed that certain cargo, such as Semaphorin 3A (Sema3A), was delivered at the cell surface as stable deposits. Stable deposits and transient events were observed for single cargo and both were SNARE (soluble $\mathrm{N}$-ethylmaleimide-sensitive factor attachment protein receptor) and calcium dependent. The ratio between stable and transient events did not depend on cargo size, subcellular localization (synaptic vs extrasynaptic secretion), or the presence of the extracellular matrix. Instead, the ratio is cargo specific and depends on an interaction with the vesicle matrix through a basic domain in the cargo protein. Inhibition of this interaction through deletion of the basic domain in Sema3A abolished stable deposits and rendered all events transient. Strikingly, cargo favoring transient release was stably deposited after corelease with cargo favoring stable deposit. These data argue against cargo diffusion after exocytosis as a general principle. Instead, the vesicle matrix retains secreted signals, probably for focal signaling at the cell surface.
\end{abstract}

Key words: exocytosis; activity-dependent secretion; peptidergic release; neurons; synaptic plasticity; large dense-core vesicles

\section{Introduction}

Communication between neurons is mediated by the regulated secretion of molecules from two main classes of secretory vesicles: small synaptic vesicles and larger secretory (dense-core) granules. Synaptic vesicles release neurotransmitters at the presynaptic terminal, whereas the less precisely defined class of secretory granules mediates secretion of a diverse array of proteins with important roles in neuronal development and plasticity, such as neuropeptides, neurotrophic factors, guidance cues, and proteases (Parmer et al., 1997; Haubensak et al., 1998; McAllister et al., 1999; Pang and Lu, 2004; Sahay et al., 2005; Bouzioukh et al., 2006; de Wit et al., 2006; Morita et al., 2006). Despite its importance for neuronal function, secretory granule exocytosis in neurons remains poorly understood.

It has been suggested that secretory granule exocytosis in neurons is similar to peptide/hormone secretion in neuroendocrine

Received Aug. 18, 2008; revised Nov. 21, 2008; accepted Nov. 23, 2008.

This work was supported by grants from the Netherlands Organization for Scientific Research (GBMW 903-42023 to R.F.T., GpD 970-10-036 to M.V., ZonMW Veni Grant 016-066-101 to R.F.T., and ZonMW-Pionier Grant 90001-001 to M.V.), The NeuroBsik Mouse Phenomics Consortium (BSIK03053), and the European Commission (the EUSynapse project, LSHM-CT-2005-019055). We thank Desiree Schut, Robbert Zalm, and Ingrid Saarloos for excellent technical assistance and Tatiana Boiko for comments on this manuscript.

Correspondence should be addressed to Prof. Matthijs Verhage, Department of Functional Genomics, Center for Neurogenomics and Cognitive Research, Vrije Universiteit Amsterdam (VUA) and VUA Medical Center, De Boelelaan 1087, 1081 HV Amsterdam, The Netherlands. E-mail: matthijs.verhage@cncr.vu.nl.

J. de Wit's present address: Division of Biological Sciences, Neurobiology Section, University of California, San Diego, 1118 Pacific Hall, 9500 Gilman Drive, La Jolla, CA 92093.

DOI:10.1523/JNEUROSCI.3931-08.2009

Copyright (C) 2009 Society for Neuroscience $\quad 0270-6474 / 09 / 290023-15 \$ 15.00 / 0$ cells, which has been intensely studied. The release characteristics of secretory granules in these cells are complex: in addition to classical full fusion, secretory granules sometimes release only a fraction of their content. This appears to be attributable to two main factors. First, fusion pores can open only transiently and the fusion machinery restricts cargo diffusion out of the vesicle (Lindau and Almers, 1995; Artalejo et al., 1998; Alés et al., 1999). Second, electrostatic interactions between the luminal matrix consisting of charged (glyco)proteins and basic residues in condensed cargo restrict cargo diffusion (Kelly, 1985; Arvan and Castle, 1998). The strength of these interactions is modulated by intravesicular $\mathrm{pH}$ and cellular cAMP levels (Aspinwall et al., 1997; Angleson et al., 1999). As a result of these interactions and transient fusion pore opening, secretory vesicles can reseal directly after exocytosis (Holroyd et al., 2002; Taraska et al., 2003), retaining part of their cargo. This may facilitate cargo reuse and regulate the extent of cargo release (Taraska et al., 2003; An and Zenisek, 2004; Perrais et al., 2004; Scalettar, 2006). Hence, secretory granules in neuroendocrine cells undergo exocytosis through at least two distinct mechanisms: full fusion and incomplete exocytosis followed by reinternalization of the partially emptied vesicle. Whether these mechanisms also exist in neurons is unclear. Neuronal exocytosis may differ from neuroendocrine cells (Silverman et al., 2005).

Here we investigated neuronal secretory granule release using live imaging of vesicles transporting cargo tagged with superecliptic pHluorin, a $\mathrm{pH}$-sensitive green fluorescent protein (Miesenböck et al., 1998; Sankaranarayanan et al., 2000), to de- 

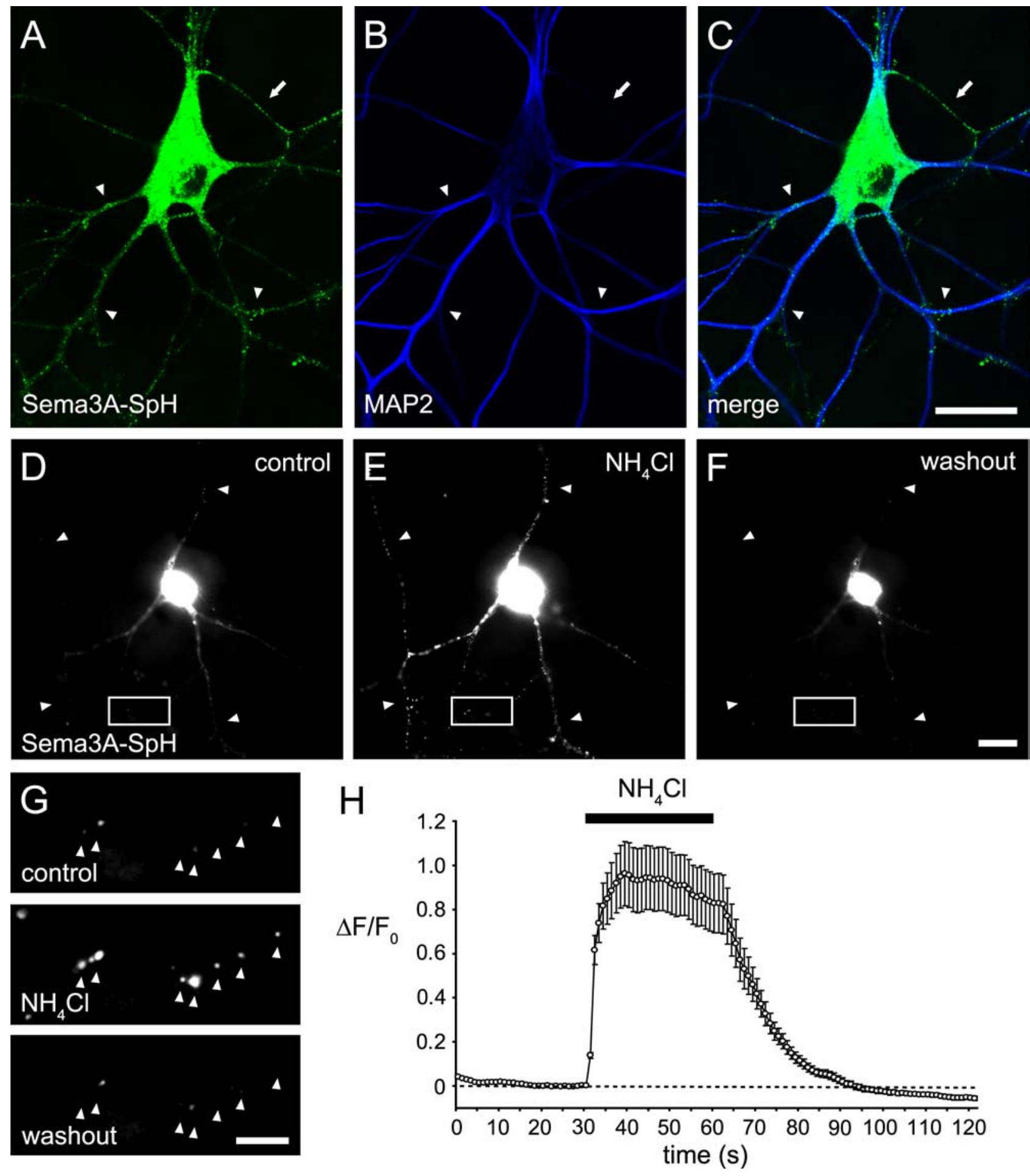

Figure 1. Characterization of SemapHluorin in cortical neurons. A, Punctate SemapHluorin distribution in fixed and permeabilized cell (DIV 16). $\boldsymbol{B}$, MAP2-positive dendrites of neuron in $\boldsymbol{A}$. C , Merged image shows SemapHlluorin puncta in dendrites (arrowheads) and axon (arrow). $\boldsymbol{D}$, Live image of SemapHluorin-expressing cortical neuron (DIV 22). $\boldsymbol{E}, \mathrm{NH}_{4} \mathrm{Cl}$ application results in the appearance of many bright fluorescent puncta in neurites (arrowheads). The brightness of the soma also increases after application of $\mathrm{NH}_{4} \mathrm{Cl}$, presumably because of an increase in $\mathrm{SemapHluorin}$ fluorescence in the Golgi apparatus, which is slightly acidic ( $\mathrm{pH} \sim 6.2$ ) (Ashby et al., 2004). $\boldsymbol{F}$, SemapHluorin fluorescence returns to baseline levels after washout of $\mathrm{NH}_{4} \mathrm{Cl}$. $\boldsymbol{G}$, Blow-up of boxed region in $\boldsymbol{D}-\boldsymbol{F}$. $\mathrm{NH}_{4} \mathrm{Cl}$ application visualizes SemapHluorin puncta that disappear again after washout of $\mathrm{NH}_{4} \mathrm{Cl}$. $\boldsymbol{H}$, SemapHluorin fluorescence $\left(\Delta F / F_{0}\right)$ after $\mathrm{NH}_{4} \mathrm{Cl}(n=40$ puncta, 3 cells). Stable puncta were selected for quantification. Black bar indicates duration of $\mathrm{NH}_{4} \mathrm{Cl}$ application. Scale bars: $\boldsymbol{C}$ (for $\left.\boldsymbol{A}-\boldsymbol{C}\right), \boldsymbol{F}($ for $\boldsymbol{D}-\boldsymbol{F}), 20 \mu \mathrm{m} ; \boldsymbol{G}, 5 \mu \mathrm{m}$.

tect individual fusion events. In addition to the release events previously observed in neuroendocrine cells, we found that certain cargo types are delivered as stable deposits at the cell surface, especially the guidance cue Semaphorin $3 \mathrm{~A}$ (Sema3A), the protease tissue plasminogen activator (tPA), and the neurotrophin brain-derived neurotrophic factor (BDNF). These stable deposits, like transient fusion events, were $\mathrm{Ca}^{2+}$ and soluble $\mathrm{N}$-ethylmaleimide-sensitive factor attachment protein receptor (SNARE) dependent and occurred at both synaptic and extrasynaptic locations and at locations with and without extracellular 
matrix. Coexpression of two cargo types in single vesicles shifted the ratio between transient and persistent events. Moreover, inhibiting the interaction between the vesicle matrix and the basic residues of Sema3 A abolished the stable deposits and rendered all fusion events transient.

\section{Materials and Methods}

Cell culture and transfections. Cerebral cortices from C57BL/6 mouse E18 embryos were dissected free of meninges in HBSS (Invitrogen) supplemented with $7 \mathrm{~mm}$ HEPES and digested with $0.25 \%$ trypsin (Invitrogen) in HBSS/HEPES for $20 \mathrm{~min}$ at $37^{\circ} \mathrm{C}$. Tissue was washed three times in HBSS/HEPES and triturated with a fire-polished glass pipette. Dissociated neurons were plated at a density of 25,000 cells/well on top of a layer of rat glial cells grown at a density of 37,500 cells/well on $18 \mathrm{~mm}$ glass coverslips (Menzel Glaser) in 12-well plates. Cells were grown in Neurobasal medium (Invitrogen) supplemented with B27 (Invitrogen), $18 \mathrm{~mm}$ HEPES, 0.5 mM Glutamax (Invitrogen), $25 \mu \mathrm{M} \beta$-mercaptoethanol, and penicillin/streptomycin (Invitrogen). Half the medium was replaced once a week. Calcium phosphate transfections were performed as described previously (Köhrmann et al., 1999). Cells were routinely transfected at 6-8 d in vitro (DIV) and imaged between 14 and 22 DIV. For tetanus neurotoxin experiments, cells were transfected at 11 DIV with Lipofectamine 2000 (Invitrogen) according to the manufacturer's instructions and imaged at DIV 14 . The transfection procedure used mainly transfects neurons but occasionally results in a transduced glial cell. However, these are easily distinguished from neurons by their distinct morphology and were not included in this study. In addition, the neuronal identity of the cells imaged in this study was verified by retrospective immunocytochemistry for the dendritic marker MAP2 in a number of the experiments.

Plasmids. SemapHluorin was generated by replacing EGFP in Sema3A-EGFP (De Wit et al., 2005) with the superecliptic pHluorin $(\mathrm{SpH})$ coding sequence. $\mathrm{tPA}-\mathrm{SpH}$ and neuropeptide $\mathrm{Y}(\mathrm{NPY})-\mathrm{SpH}$ were generated by replacing EGFP or Venus with $\mathrm{SpH}$. BDNF-SpH was generated by PCR amplifying prepro-BDNF cDNA from an adult rat cDNA library and subcloning it into the EGFP-N1 vector (Clontech) in which EGFP had been replaced with $\mathrm{SpH}$. Sema $\Delta \mathrm{BD}$ was generated by amplifying SemapHluorin minus the basic domain (amino acids $728-770$ in rat Sema3A) using the following primers: cgggatccgcaaacggaaagaacaatg and gccgcggccgctcagacactccacacttgttcacagaactcatc. The resulting fragment was ligated into the SemapHluorin expression plasmid. Tetanus neurotoxin (TeNT)-IRES-mRFP was generated by subcloning the TeNT light chain and poliovirus IRES sequence into an mRFP-N1 backbone (Clontech). SpH and synaptopHluorin were kindly provided by Dr. G. Miesenböck (Yale University School of Medicine, New Haven, CT); synaptophysin-mCherry by Dr. A. Jeromin (Allen Institute for Brain Science, Seattle, WA); tetanus toxin light chain by Dr. T. Galli (INSERM, Paris, France); NPY-Venus by Dr. A. Miyawaki (Brain Science Institute, RIKEN, Saitama, Japan); and tPA-GFP by Dr. B. Scalettar (Lewis and Clark College, Portland, OR). Red variants of Sema3A, tPA, and BDNF were obtained by replacing $\mathrm{SpH}$ with mRFP.

Live cell imaging. Coverslips were placed in a chamber containing Tyrode's solution $\left(2 \mathrm{~mm} \mathrm{CaCl}_{2}, 2.5 \mathrm{~mm} \mathrm{KCl}, 119 \mathrm{~mm} \mathrm{NaCl}, 2 \mathrm{~mm} \mathrm{MgCl}, 30\right.$ mM glucose, and 25 mm HEPES, pH 7.4) and imaged on an Axiovert II microscope (Zeiss) equipped with a heated stage $\left(\sim 32^{\circ} \mathrm{C}\right)$, a Coolsnap HQ camera (Photometrics), and a Polychrome IV illumination unit (TILL Photonics). Cells were continuously perfused with Tyrode's. Images were acquired in MetaMorph 6.2 software (Universal Imaging) using a $40 \times$ objective. Cells were stimulated with a triple-barreled pipette positioned near the imaged cell, which allowed for quick changes in the composition of stimulating solutions. Depolarizing Tyrode's solution contained $60 \mathrm{~mm} \mathrm{KCl}\left(2 \mathrm{~mm} \mathrm{CaCl}_{2}, 60 \mathrm{~mm} \mathrm{KCl}, 61.5 \mathrm{~mm} \mathrm{NaCl}, 2 \mathrm{~mm}\right.$ $\mathrm{MgCl}_{2}, 30 \mathrm{~mm}$ glucose, and $25 \mathrm{~mm}$ HEPES, $\mathrm{pH}$ 7.4). Intracellular $\mathrm{pH}$ was neutralized with normal Tyrode's solution containing $50 \mathrm{~mm} \mathrm{NH}_{4} \mathrm{Cl}$, which replaced $\mathrm{NaCl}$ on an equimolar basis in the solution. Low- $\mathrm{pH}(\mathrm{pH}$ 5.5) Tyrode's used for acid wash experiments was identical to normal Tyrode's except that HEPES was replaced with the membraneimpermeant buffer 2-(N-morpholino)ethanesulfonic acid. Tyrode's
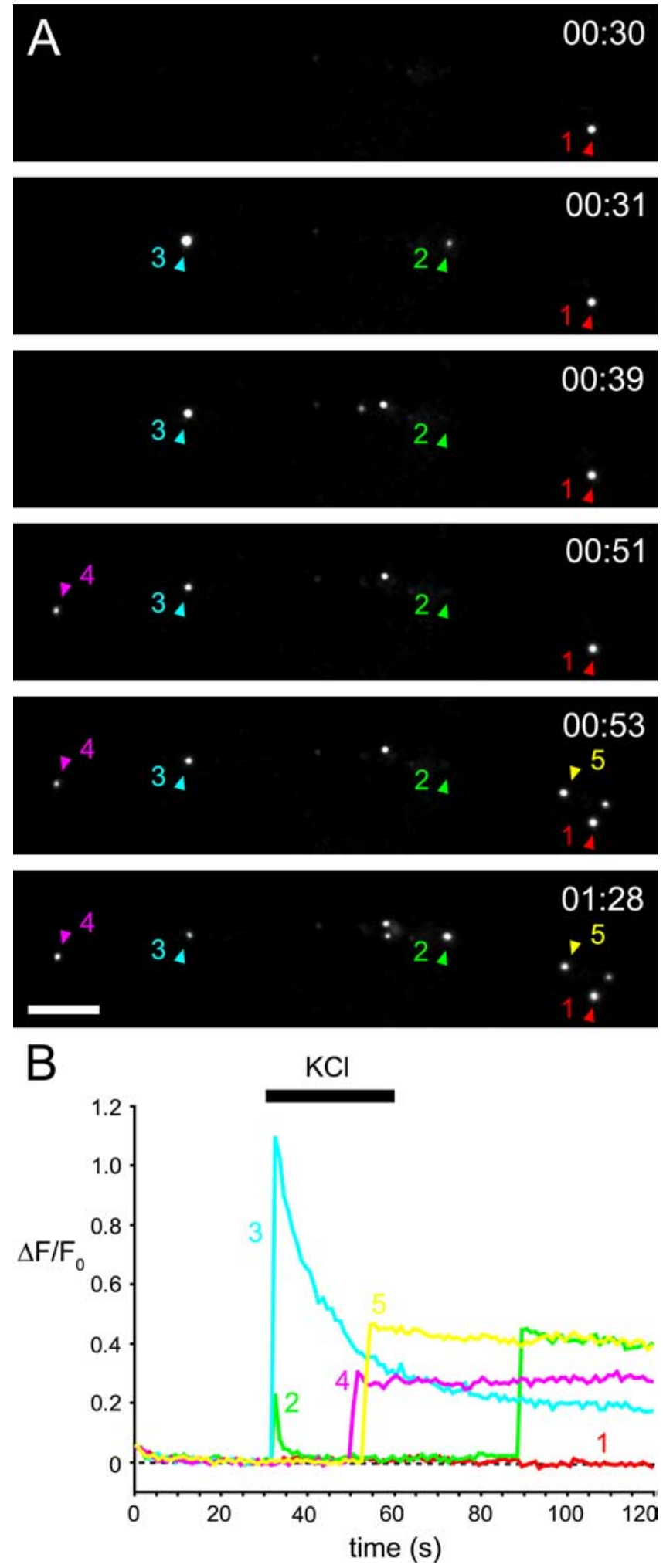

Figure 2. Visualization of SemapHlluorin secretion in neurons. $A$, Movie frames (supplemental Movie 1, available at www.jneurosci.org as supplemental material) showing an axonal segment of a cortical neuron (DIV 22). Application of a $30 \mathrm{~s}, 60 \mathrm{~mm} \mathrm{~K}^{+}$stimulus results in the abrupt appearance of bright puncta along the axon (arrowheads). Representative events are indicated with numbered, colored arrowheads. $B$, Normalized fluorescence $\left(\Delta F / F_{0}\right)$ of the events indicated in $A$. Traces are shown in the corresponding colors. Black bar indicates duration of stimulus. Scale bar, $5 \mu \mathrm{m}$. 
A Transient
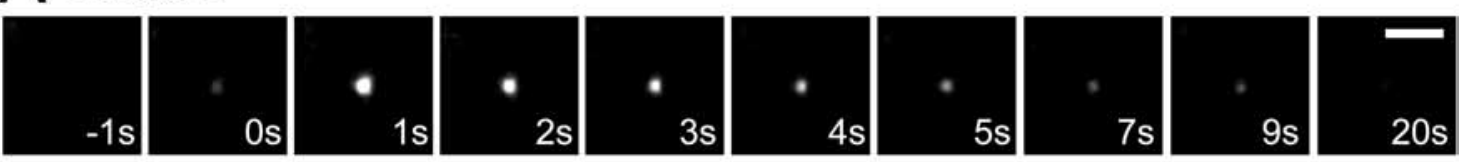

Persistent
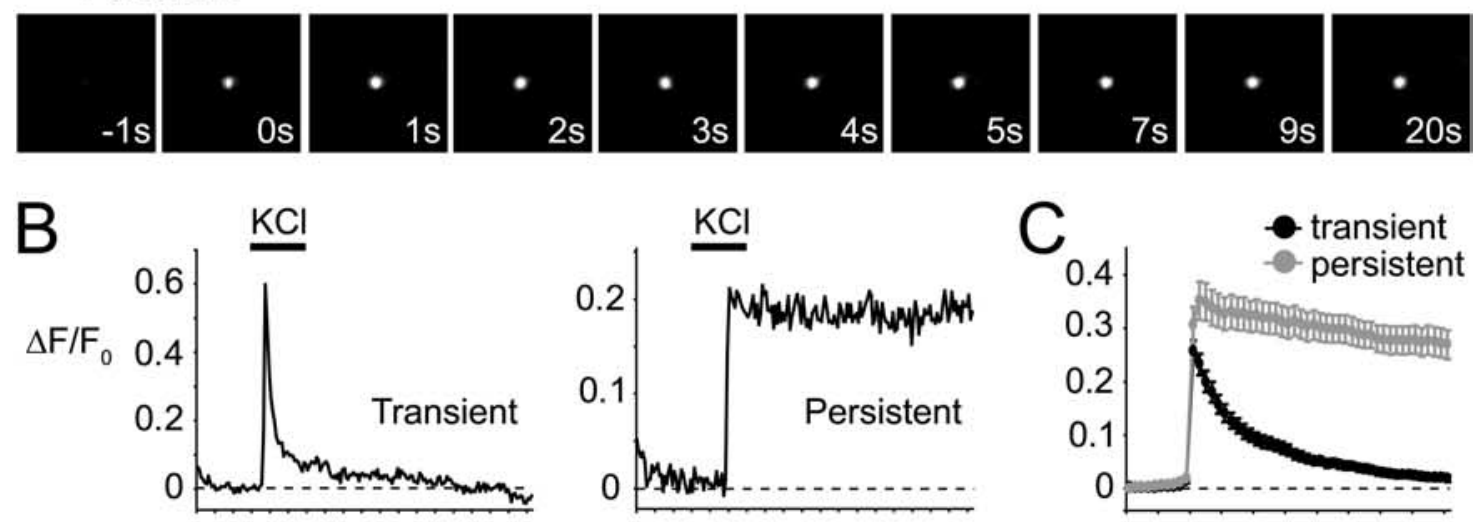

D
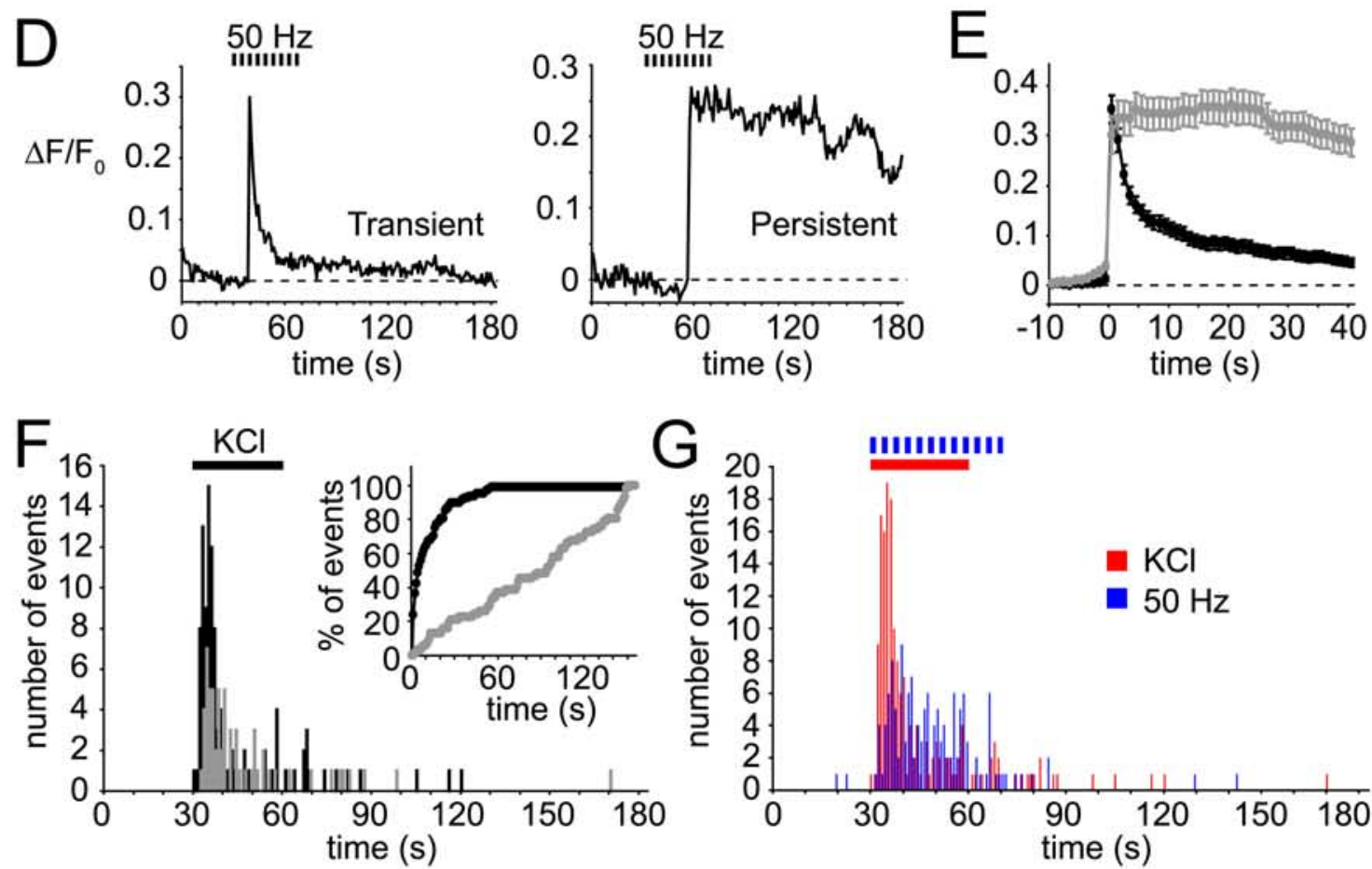

$\mathrm{H}$
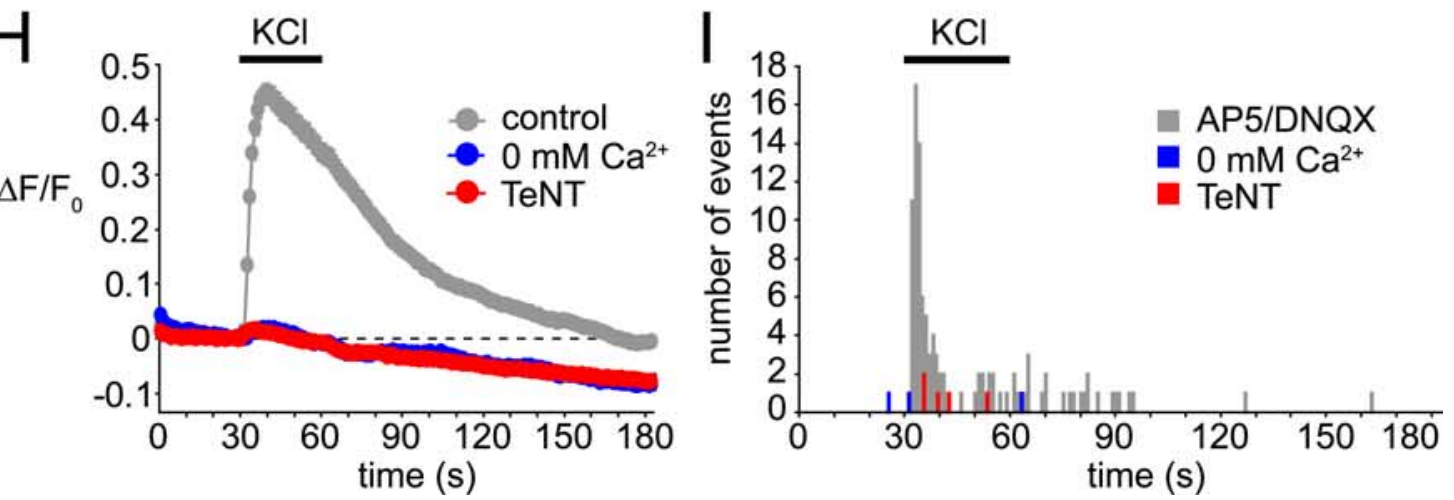

Figure 3. Transient and persistent fusion events after secretion of SemapHluorin. $\boldsymbol{A}$, Movie frames illustrating representative transient (top; supplemental Movie 2, available at www.jneurosci.org as supplemental material) and persistent (bottom; supplemental Movie 3, available at www.jneurosci.org as supplemental material) events after application of $K^{+}$. One out of 172 analyzed events could not be unequivocally categorized. Time is normalized to the frame in which events first appear above background $(t=0 \mathrm{~s})$. $\boldsymbol{B}$, Fluorescence $\left(\Delta F / F_{0}\right)$ of the events shown in $\boldsymbol{A}$. (Figure legend continues.) 
containing $0 \mathrm{mM} \mathrm{Ca}^{2+}$ and $5 \mathrm{~mm}$ EGTA was used as a control $(0 \mathrm{~mm}$ $\mathrm{CaCl}_{2}, 5 \mathrm{~mm}$ EGTA, $60 \mathrm{~mm} \mathrm{KCl}, 61.5 \mathrm{~mm} \mathrm{NaCl}, 4 \mathrm{~mm} \mathrm{MgCl}, 30 \mathrm{~mm}$ glucose, and $25 \mathrm{~mm}$ HEPES, $\mathrm{pH}$ 7.4). Field stimulation was applied through parallel platinum electrodes immersed into the perfusion chamber, delivering $30 \mathrm{~mA}, 1 \mathrm{~ms}$ pulses, using a Master8 stimulator (AMPI) and a Stimulus Isolator A385 (World Precision Instruments). The effectiveness of depolarizing solution and field stimulation was verified by the ability to induce synaptic secretion from synaptopHluorin-expressing neurons.

For FM4-64 labeling experiments, terminals were loaded with a train of 600 pulses at $20 \mathrm{~Hz}$ in the presence of $10 \mu \mathrm{M}$ FM4-64 (Invitrogen). After $1 \mathrm{~min}$, cells were washed by perfusion with dye-free Tyrode's for 10 min. Cells were destained by the application of $60 \mathrm{~mm} \mathrm{KCl} \mathrm{Tyrode's} \mathrm{for} 1$ min. Images were taken of the FM4-64 signal before and after depolarization and subtracted to exclude background labeling. For tetanus neurotoxin experiments, cells were cotransfected with synaptopHluorin or SemapHluorin, TeNT-IRES-mRFP, and pECFP-C1 (Clontech) to visualize distant neurites, because mRFP expression from the second cistron only labeled the cell body. Imaged neurites were traced back to the soma to verify expression of all three plasmids in imaged cells. For the quantification of secretion in the presence of bafilomycin, synaptopHluorin- or SemapHluorin-expressing cells were first stimulated in the absence of bafilomycin. After a 10 min wash with Tyrode's, $1 \mu \mathrm{M}$ bafilomycin A1 (Sigma) was applied to the cells for $30 \mathrm{~s}$ and washed out again by perfusion with Tyrode's. Imaging was started within $1 \mathrm{~min}$ after application of bafilomycin. Analysis of SemapHluorin release in the absence or presence of bafilomycin was done blind to the treatment condition. DNQX was from Sigma, and APV was from Tocris.

For analysis of interaction with the extracellular matrix, medium was supplemented with heparin $(0.1 \mathrm{mg} / \mathrm{ml}$, Sigma $) 24 \mathrm{~h}$ before image acquisition or with chondroitinase $\mathrm{ABC}$ (chonABC, $0.1 \mathrm{U} / \mathrm{ml}$ for $2 \mathrm{~h}$, Sigma) or hyaluronidase (500 $\mu \mathrm{U} / \mathrm{ml}$ for $18 \mathrm{~h}$, Calbiochem). Treatment with these substances resulted in a loss of Sema3A deposits (or "halo") on the supporting glial cells. The efficiency of chondroitinase treatment was further evaluated using antibody 2B6, which detects chondroitin sulfate stubs generated after chonABC treatment (De Wit et al., 2005). Hyaluronidase efficiency was examined by incubating live neurons with biotinylated hyaluronic acid-binding protein (HABP, $5 \mu \mathrm{g} / \mathrm{ml}$, USBiological) for $18 \mathrm{~h}$ at $37^{\circ} \mathrm{C}$, after which cells were fixed and incubated with Alexa564 streptavidin. HABP labeling resulted in a punctate expression pattern, which was absent in hyaluronidase-treated cultures.

Image analysis. Stacks from time-lapse recordings acquired with $1 \mathrm{~s}$ intervals were used to analyze the dynamics of SemapHluorin release. SemapHluorin release events were detected by eye while playing movie stacks. A $4 \times 4$ pixel region of interest was centered on the event, and average intensity of fluorescence therein was measured. Fluorescent traces were graphed as the change in fluorescence $(\Delta F)$ normalized to the initial fluorescence $\left(F_{0}\right)$, obtained by averaging the last five frames before onset of stimulus, as a function of time. Onset of exocytosis was defined as the first frame in which the average fluorescence increased above a threshold of $\Delta F / F_{0}=0.1$. Transient events were defined as an abrupt increase in fluorescence, followed by a rapid decrease back to baseline levels (typically $<30 \mathrm{~s}$ in $90 \%$ of events); persistent events were characterized by an abrupt increase in fluorescence that remained elevated above baseline (typically $>30 \mathrm{~s}$ in $80 \%$ of events). Events were defined as transient if an event lost $>50 \%$ of the peak $\Delta F / F_{0}$ fluorescence at $50 \%$ of the time that the fluorescence was above baseline. Duration of events was defined as the time that the average fluorescence remained above the threshold of $\Delta F / F_{0}=0.1$. For experiments in which cells were sequentially stimulated with $\mathrm{K}^{+}$and $\mathrm{NH}_{4} \mathrm{Cl}$ or low-pH Tyrode's, the local background was determined by measuring the average fluorescence in a $10 \times$ 10 pixel region next to the release event and subtracting this value from the event. Background subtraction was mainly required after acid wash experiments, because of the presence of secreted SemapHluorin adhering to the substrate around imaged neurites, which strongly reacted to perfusion with low-pH Tyrode's. Movement of fluorescent spots was analyzed by manually tracking the center of spots using the "track points" function in MetaMorph. Spots were tracked for $30 \mathrm{~s}$ after their appearance, and the total distance moved during this period was calculated.

For representation in figures, original MetaMorph images were duplicated at $200 \%$ zoom to reduce pixelation, using the interpolation function in MetaMorph to compute the values for each new pixel based on the original values surrounding it. Data analysis was always performed on the original images.

Immunocytochemistry. Cells were fixed in $4 \%$ paraformaldehyde in PBS, pH 7.4, for $20 \mathrm{~min}$ at room temperature (RT). Cells were washed in PBS and blocked in PBS-FBS [PBS containing 5\% fetal bovine serum (FBS, Invitrogen) and $0.2 \%$ Triton X-100] for $1 \mathrm{~h}$ at RT. Incubations with primary antibodies were done overnight at $4^{\circ} \mathrm{C}$ in PBS-FBS. Primary antibodies used were MAP2 mAb (Millipore) and synapsin I/II pAb (E028). Alexa Fluor-conjugated secondary antibodies were from Invitrogen. After several washes, coverslips were mounted in ProLong antifade reagent (Invitrogen) and examined on a Zeiss LSM 510 confocal laserscanning microscope. Specificity of staining was confirmed by omission of the primary antibody. For live-cell labeling of imaged neurons, cells were removed from the stage, briefly washed with PBS, and incubated with GFP pAb (Abcam) in PBS for 5 min at RT. Cells were quickly washed in PBS and fixed. After three washes in PBS, cells were incubated with Alexa Fluor-conjugated anti-rabbit antibody. Cells were washed, permeabilized in PBS-FBS, and subsequently processed for MAP2 immunocytochemistry.

\section{Results}

\section{Secretory granules in primary neurons undergo transient and} persistent fusion events

To visualize secretory granule exocytosis in neurons, we generated a series of constructs expressing secretory granule cargo tagged with SpH (Miesenböck et al., 1998; Sankaranarayanan et al., 2000): NPY-SpH, the neurotrophin BDNF-SpH, the protease tPA-SpH, and the guidance cue Sema3A-SpH. These cargo types were expressed in dissociated cortical neurons and analyzed using live-cell imaging.

We first analyzed whether different release events (complete vs incomplete release), as previously characterized in neuroendocrine cells (Holroyd et al., 2002; Taraska et al., 2003; Perrais et al., 2004), also occur in neurons using Sema3A-SpH (SemapHluorin) as a marker. Expression of SemapHluorin in dissociated neurons resulted in a characteristic punctate distribution (Fig. $1 A-C)$, in accordance with the vesicular localization of endogenous Sema3A and Sema3A-EGFP (de Wit et al., 2006). Application of $\mathrm{NH}_{4} \mathrm{Cl}$ strongly increased the fluorescence of these puncta (Miesenböck et al., 1998) and revealed many new fluorescent puncta (Fig. $1 D-H$ ), indicating that SemapHluorin is correctly sorted to acidic secretory vesicles and can be used to assess secre-

(Figure legend continued.) C, Averaged traces for transient (black circles) and persistent events (gray circles) after $\mathrm{K}^{+}$(mean \pm SEM; $n=171$ events, 8 cells). $\boldsymbol{D}$, Representative traces of transient and persistent fusion events after electrical stimulation (16 bursts of 50 pulses at $50 \mathrm{~Hz}$ spaced within $40 \mathrm{~s}$ ). E, Averaged traces for transient (black circles) and persistent (gray circles) events after 50 Hz stimulus ( $n=141$ events, 9 cells). $\boldsymbol{F}$, The onset of transient (black bars) and persistent (gray bars) events after $K^{+}$. Inset, Cumulative graph plotting the duration (defined as the time $\Delta F / F_{0}$ was $>0.1$ ) of transient (black circles) and persistent (gray circles) events after $\mathrm{K}^{+}$stimulus. $\mathbf{G}$, Onset of combined transient and persistent events after $\mathrm{K}^{+}$(red bars) or $50 \mathrm{~Hz}$ stimulus (blue bars) plotted against time. Two rare spontaneous events occurred before stimulus. $\boldsymbol{H}$, Fluorescence $\left(\Delta F / F_{0}\right)$ of synaptopHluorin in response to $\mathrm{K}^{+}$(gray circles; $n=77$ boutons, 4 cells), in the absence of extracellular $\mathrm{Ca}^{2+}$ (blue circles; $n=26$ boutons, 2 cells), and in cells expressing TeNT-IRES-mRFP (red circles; $n=50$ boutons, 5 cells). $I$, Appearance of SemapHluorin events in $\mathrm{K}^{+}$-stimulated cells in normal Tyrode's with $50 \mu \mathrm{m}$ AP5 and $10 \mu \mathrm{m}$ DNQX (gray bars; $n=108$ events, 7 cells), in the absence of extracellular (a ${ }^{2+}$ (blue bars; $n=3$ events, 9 cells), and in cells expressing TeNT-IRES-mRFP (red bars; $n=5$ events, 9 cells). Solid bars and dashed bars indicate duration of $\mathrm{K}^{+}$and $50 \mathrm{~Hz}$ stimulus, respectively. Scale bar, $2 \mu \mathrm{m}$. 
tory vesicle exocytosis in neurons at single vesicle resolution. Correct sorting was also confirmed for SpH-fusions of NPY, tPA, and BDNF (data not shown). All four cargo proteins are normally expressed in cortical neurons (Higuchi et al., 1988; Hofer et al., 1990; Giger et al., 1996; Basham and Seeds, 2001).

Depolarization of SemapHluorin-expressing neurons with 60 $\mathrm{mM} \mathrm{K}^{+}$resulted in the abrupt appearance of many bright fluorescent puncta (Fig. 2 A; supplemental Movie 1, available at www. jneurosci.org as supplemental material). Some of these puncta dimmed rapidly (Fig. 2, vesicle 2), whereas others dimmed slowly (vesicle 3). Strikingly, a number of puncta remained bright (vesicles 4 and 5) without appreciable decline in fluorescence. All these events occurred with varying delays after onset of stimulus and at multiple locations along the axon. Interestingly, after vesicle 2 had dimmed completely, a bright spot reappeared at the same location. Hence, different types of release events were apparent in cultured neurons. Rapidly or slowly dimming fluorescent signals may reflect complete release followed by cargo diffusion and/or incomplete release followed by reacidification, as previously observed in non-neuronal cells (Holroyd et al., 2002; Taraska et al., 2003; Perrais et al., 2004). However, the persistent events appear to be a novel type of release event, which may be specific for neurons and/or Sema3A cargo (see below).

Of the fusion events induced by $\mathrm{K}^{+}$depolarization in each cell, $63 \pm 6 \%$ were transient (mean \pm SEM; $n=172$ events, 8 cells) (Fig. 3A, $B$; supplemental Movie 2, available at www. jneurosci.org as supplemental material) (see Materials and Methods for a definition of transient and persistent events). Similar results were obtained for electrical stimulation: $62 \pm 7 \%$ of the events were transient ( $n=141$ events, 9 cells) (Fig. $3 D$ ). Transient events had an average decay time constant of $8.7 \pm 0.3 \mathrm{~s}$ for chemical (Fig. 3C) and $4.7 \pm 0.3 \mathrm{~s}$ for electrical (Fig. 3E) stimulation. Persistent events on the other hand remained visible as discrete spots for as long as $2 \mathrm{~min}$ after the stimulus had ended (Fig. $3 A, B, D$; supplemental Movie 3, available at www.jneurosci.org as supplemental material) and accounted for $36 \pm 6 \%$ of total events for chemical and $38.2 \pm 6.8 \%$ for electrical depolarization. Both types of events occurred at variable delays after onset of stimulus, but were rarely observed before depolarization (Fig. $3 F$ ). A cumulative plot of the event duration (defined as the time $\Delta F / F_{0}$ was above a threshold of 0.1) confirms the existence of at least two distinct classes of events (Fig. 3F, inset). According to this criterion, transient events had an average duration of $12 \pm 2 \mathrm{~s}$ (109 events), whereas persistent events had an average duration of $84.2 \pm 6 \mathrm{~s}$ (62 events). Release after electrical stimulation was more protracted than the sharp peak observed after $\mathrm{K}^{+}$-induced release (Fig. $3 G$ ), possibly because of a slower buildup of internal $\mathrm{Ca}^{2+}$ levels compared with $\mathrm{K}^{+}$-induced depolarization.

The increase in fluorescence after depolarization varied per event (Figs. $2 B, 3 B, D$ ). To determine whether this difference in fluorescence increase is caused by a difference in the amount of SemapHluorin cargo per vesicle, cells were sequentially stimulated with $\mathrm{K}^{+}$and $\mathrm{NH}_{4} \mathrm{Cl}$ to reveal the total amount of SemapHluorin per vesicle (supplemental Fig. S1, available at www. jneurosci.org as supplemental material) (and see below). We quantified the ratio between the peak response in fluorescence after $\mathrm{K}^{+}$ and the peak response in fluorescence after $\mathrm{NH}_{4} \mathrm{Cl}$ for transient events that responded to both stimuli. The ratio between these two responses is $0.90 \pm 0.06$ (mean \pm SEM; $n=41$ events, 15 cells), and the correlation coefficient $R^{2}$ of these two responses is 0.987 (supplemental Fig. S1, available at www.jneurosci.org as supplemental material), suggesting that the extent of fluorescence increase after $\mathrm{K}^{+}$stimulation reflects the total amount of
SemapHluorin cargo in the vesicle. The fluorescent events that appeared after depolarization displayed very little movement. Manual tracking of the center of persistent events for the first $30 \mathrm{~s}$ after their appearance showed that the spots moved on average $0.076 \pm 0.02 \mu \mathrm{m}$ during this period (mean $\pm \mathrm{SEM}$; $n=42$ events tracked, 3 cells), which is less than one pixel.

\section{All types of release events are SNARE and $\mathrm{Ca}^{2+}$ dependent}

To determine whether fusion of SemapHluorin vesicles depends on SNARE proteins, neurons were cotransfected with TeNT light chain-IRES-mRFP, which cleaves the vesicular SNARE protein synaptobrevin. As expected, expression of TeNT-IRES-mRFP abolished synaptic vesicle secretion in synaptopHluorinexpressing cells (Fig. $3 H$ ). Similarly, SemapHluorin transient and persistent events were almost completely absent in neurons expressing TeNT ( $n=5$ events, 9 cells) (Fig. $3 I$ ). In the absence of extracellular $\mathrm{Ca}^{2+}$, SemapHluorin events were also very rare ( $n=3$ events, 9 cells) (Fig. $3 I$ ), again similar to the reduction in synaptic vesicle secretion (Fig. $3 H$ ). Finally, SemapHluorin events did not require additional synaptic activation after $\mathrm{K}^{+}$induced depolarization. The presence of AMPA and NMDA receptor antagonists (DNQX, $10 \mu \mathrm{M}$ and AP5, $50 \mu \mathrm{M}$ ) did not alter the characteristics of SemapHluorin events $(n=108$ events, 7 cells) (Fig. 3I).

\section{Transient events represent complete release as well as retrieval of secretory vesicles}

To discriminate between complete release followed by cargo diffusion and incomplete release followed by resealing and reacidification, we performed three experiments. First, if SemapHluorin-containing vesicles reseal/reacidify after incomplete release, a subsequent instant application of $\mathrm{NH}_{4} \mathrm{Cl}$ should cause reappearance of dimming vesicles. Figure $4 A$ shows a typical transient event during depolarization. Instant application of $\mathrm{NH}_{4} \mathrm{Cl}$ caused the dimming vesicle to reappear and revealed at least two additional vesicles that had not responded to the $\mathrm{K}^{+}$ stimulus (Fig. 4A,B). Of 56 transient events analyzed, 63\% reappeared after $\mathrm{NH}_{4} \mathrm{Cl}(n=10$ cells), suggesting that these events represent retrieval of secretory vesicles after incomplete release. The remaining $37 \%$ of transient events did not reappear after $\mathrm{NH}_{4} \mathrm{Cl}$ and probably reflect complete release. However, alternatives such as rapid movement of reacidifying vesicles out of the field of view during $\mathrm{NH}_{4} \mathrm{Cl}$ application cannot be completely excluded. To test this, we performed a second experiment introducing a brief "acid wash," pH 5.5, directly after stimulation. If a transient event is caused by diffusion of SemapHluorin out of an open vesicle, acidification of the exterior should cause an instant decrease in fluorescence. Figure $4 C$ shows a representative transient event that appeared during stimulation and had started to dim. This vesicle continued to dim undisturbed without instant decrease in fluorescence during the subsequent acid wash (Fig. $4 C, E)$. Hence, such events originate from endocytosed and reacidifying vesicles. Sixty-one percent of the transient events did not respond to acidification of the exterior $(n=33$ events, 10 cells), whereas $39 \%$ did respond (Fig. $4 D$, vesicle 2 ). The gradually decreasing fluorescence of vesicle 2 , as well as the fluorescence of a neighboring bright vesicle (vesicle 1), was abruptly quenched after onset of the acid wash (Fig. $4 D, F$ ). The percentage of vesicles that did not respond to acidification $(61 \%)$ is in good agreement with the percentage of vesicles that reappeared after $\mathrm{NH}_{4} \mathrm{Cl}$ application (63\%).

Third, we blocked vesicle reacidification by bafilomycin A1, a specific inhibitor of the V-ATPase on secretory vesicles 

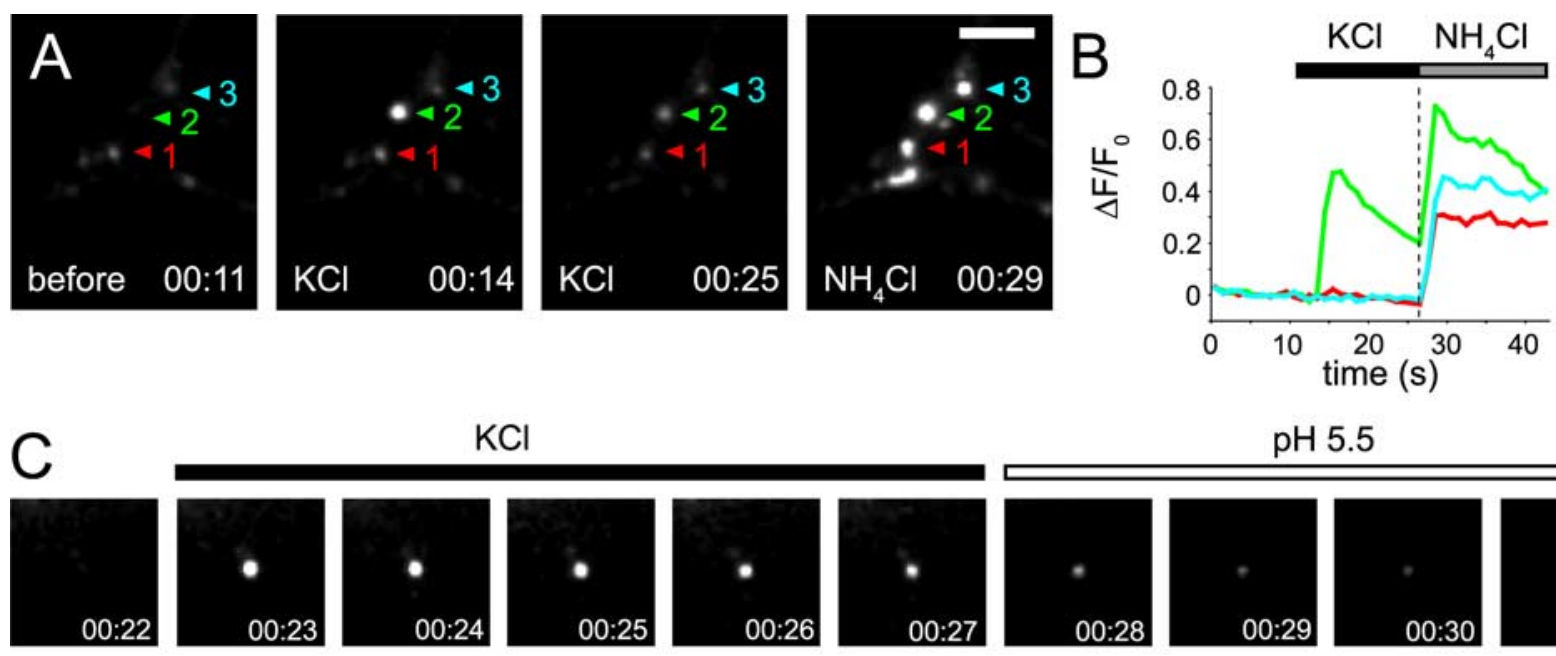

$\mathrm{pH} 5.5$

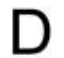

$\mathrm{KCl}$
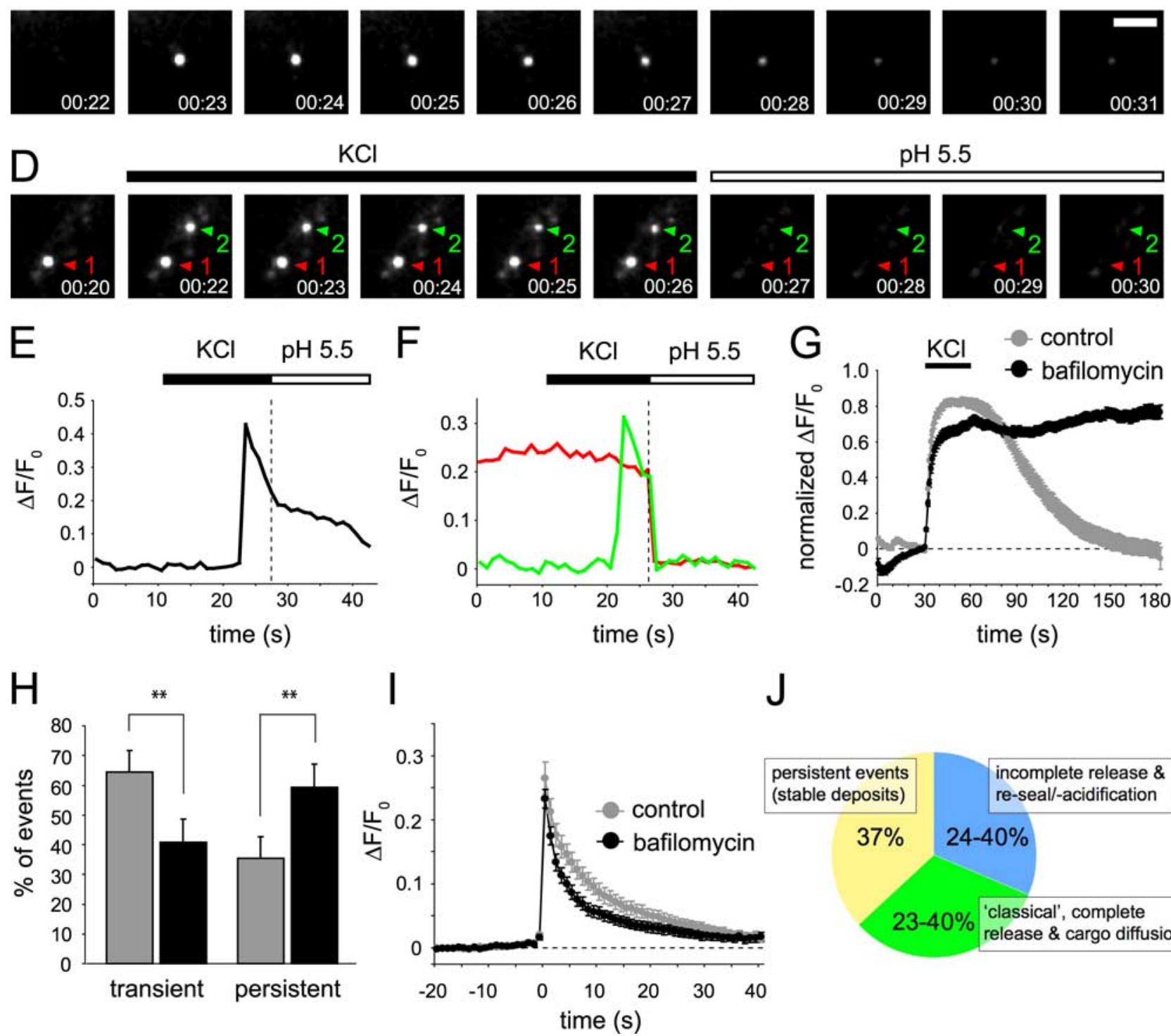

$\mathrm{pH} 5.5$

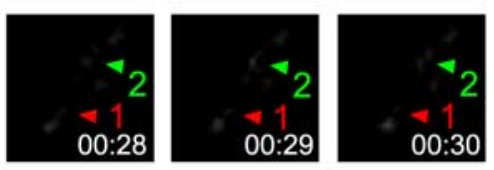

J

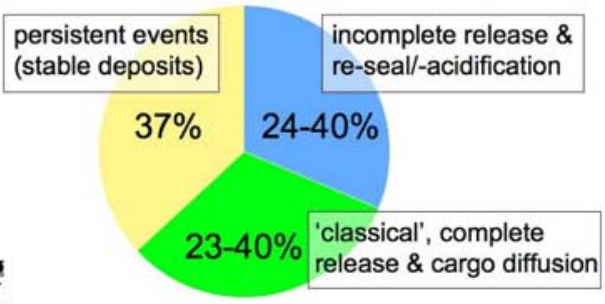

Figure 4. Retrieval of SemapHlluorin vesicles after secretion during transient fusion events. $A$, Movie frames show transient event (vesicle 2) during depolarization (KCl, $15 \mathrm{~s}$ ). Subsequent $\mathrm{NH}_{4} \mathrm{Cl}$ application $(50 \mathrm{~mm}, 15 \mathrm{~s})$ causes vesicle 2 to reappear and vesicles 1 and 3 to brighten. $\boldsymbol{B}$, Corresponding fluorescence $\left(\Delta F / F_{0}\right)$ of the events indicated with colored arrowheads in $A$. Black bar indicates duration of $\mathrm{K}^{+}$stimulus; gray bar and dotted line mark duration and onset of $\mathrm{NH}_{4} \mathrm{Cl}$ stimulus, respectively. $\mathrm{C}$, Transient SemapHluorin event continues to dim gradually after acid wash (pH 5.5), indicating that the vesicle is endocytosed and reacidifying. $\boldsymbol{D}$, Transient SemapHluorin event disappears abruptly after acid wash (vesicle 2), as does neighboring bright vesicle 1 , indicating diffusion of cargo out of an open vesicle. $\boldsymbol{E}$, Fluorescence $\left(\Delta F / F_{0}\right)$ of the event in $\boldsymbol{C}$. $\boldsymbol{F}$, Fluorescence $\left(\Delta F / F_{0}\right)$ of the numbered events in $\boldsymbol{D}$. The red trace (vesicle 1$)$ has been aligned to the trace of vesicle 2 to reflect the loss of fluorescence after acid wash, causing an upward shift. $G$, Bafilomycin blocks reacidification of synaptic vesicles. The same boutons were imaged before (gray trace) and after (black trace) application of $1 \mu \mathrm{m}$ bafilomycin and stimulated with $\mathrm{K}^{+}(n=56$ boutons, 4 cells). SynaptopHluorin fluorescence is normalized to peak response. Bafilomycin caused a spontaneous alkalinization of synaptic vesicles (Sankaranarayanan and Ryan, 2001), causing the black trace to start at a negative value (traces normalized to the first 5 frames before stimulus). $\boldsymbol{H}$, Percentage transient and persistent SemapHluorin events in the same cells before (gray bars) and after (black bars) application of $1 \mu \mathrm{m}$ bafilomycin ( $n=287$ events, 9 cells). The graph shows mean \pm SEM. I, Averaged traces for transient events in the absence (gray circles) and presence (black circles) of bafilomycin. Average decay time in the absence of bafilomycin, $\tau=8.4 \pm 0.4 \mathrm{~s}$; average decay time in the presence of bafilomycin, $\tau=4.9 \pm 0.3 \mathrm{~s}$ (mean \pm SEM). J, Distribution of SemapHluorin events. ${ }^{* *} p<0.01$, two-tailed paired $t$ test. Scale bars: $A, 2.5 \mu \mathrm{m}$; (in $C$ ) C, D, $2 \mu \mathrm{m}$. 

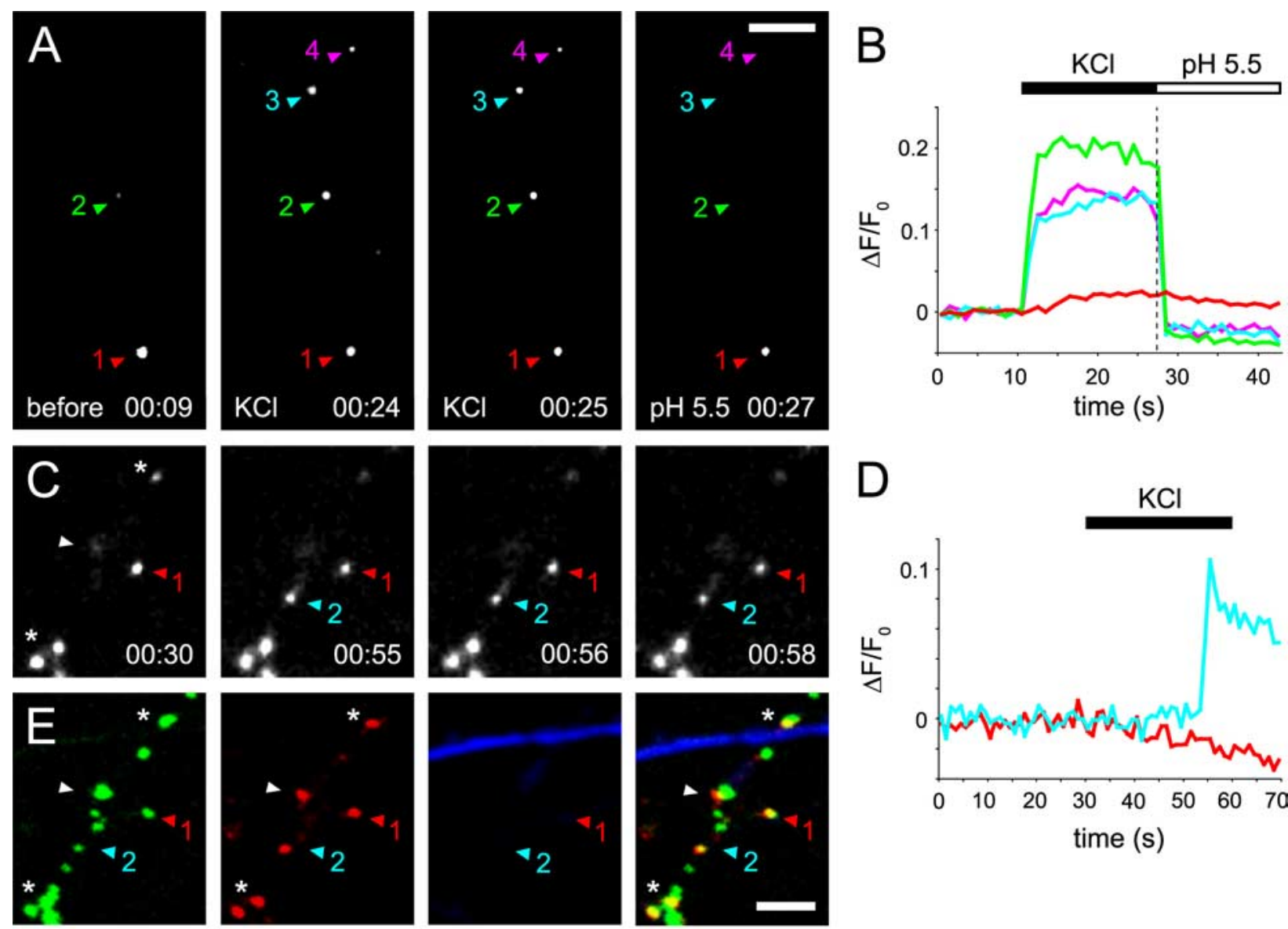

Sema3A-SpH

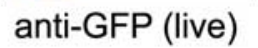

MAP2
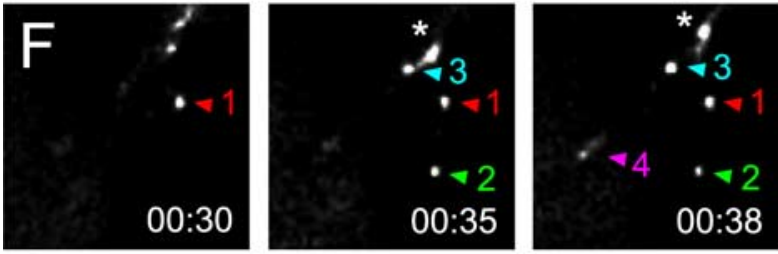

merge
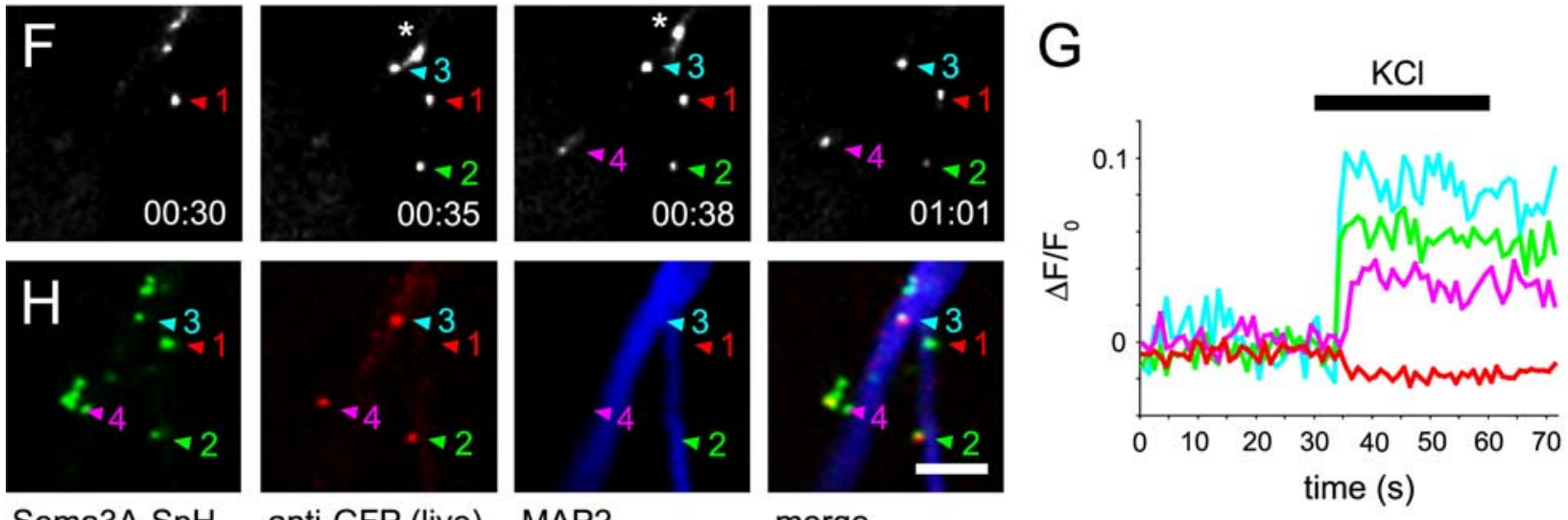

merge

Figure 5. Persistent events reflect stable deposits of SemapHluorin at the cell surface. $A$, Movie frames of an axonal segment of SemapHluorin-expressing neuron. Vesicle 2 brightens and two new persistent events (vesicles 3 and 4 ) appear during depolarization $(\mathrm{KCl}, 15 \mathrm{~s})$. These events abruptly disappear after acid wash (pH 5.5, $15 \mathrm{~s})$, indicating that cargo is accessible from the exterior. $\boldsymbol{B}$, Fluorescence $\left(\Delta F / F_{0}\right)$ of the events indicated with colored arrowheads in $A$. Black bar indicates duration of ${ }^{+}$stimulus; white bar and dotted line mark duration and onset of acid wash, respectively. C, Movie frames show a persistent event during depolarization (vesicle 2). D, Fluorescence $\left(\Delta F / F_{0}\right)$ of the events indicated with colored arrowheads in $\boldsymbol{C}$. $\boldsymbol{E}$, Anti-GFP live labeling of the axon in $\boldsymbol{C}$. The persistent event (vesicle 2 ) is live labeled with the GFP antibody. Asterisks indicate several live-labeled vesicles that were visible before stimulation in $\boldsymbol{C}$. White arrowhead indicates a live-labeled vesicle that was only faintly visible in $\boldsymbol{C}$, probably because it was out of focus during imaging. $\boldsymbol{F}$, Movie frames from a different neuron. Three new persistent events appear during depolarization (vesicles 2, 3, and 4). Asterisk indicates a bright vesicle that moved out of view. $G$, Fluorescence $\left(\triangle F / F_{0}\right)$ of the events indicated with colored arrowheads in $\boldsymbol{F}$. $\boldsymbol{H}$, Anti-GFP live labeling and MAP2 staining of the dendritic persistent events in $\boldsymbol{F}$. Scale bars: $\boldsymbol{A}, 5 \mu \mathrm{m} ; \boldsymbol{E}$ (for $\boldsymbol{C}, \boldsymbol{E}), \boldsymbol{H}$ (for $\boldsymbol{F}, \boldsymbol{H}), 2.5 \mu \mathrm{m}$.

(Dröse and Altendorf, 1997). This should abolish transient events caused by reacidification, but not those that reflect complete release and cargo diffusion. The effectiveness of bafilomycin was confirmed in synaptopHluorin-expressing neurons (Fig. 4G) (Sankaranarayanan and Ryan, 2001). In the presence of bafilomycin, the percentage of transient
SemapHluorin events was significantly reduced $(65 \pm 7 \%$ transient events before vs $41 \pm 8 \%$ after bafilomycin treatment; $n=287$ events, 9 cells; $p<0.01$ ) (Fig. $4 H$ ). This suggests that $\sim 37 \%$ of all transient events, and $24 \%$ of all events, represent retrieval of vesicles after incomplete release. The remaining transient events in the presence of bafilomycin had 

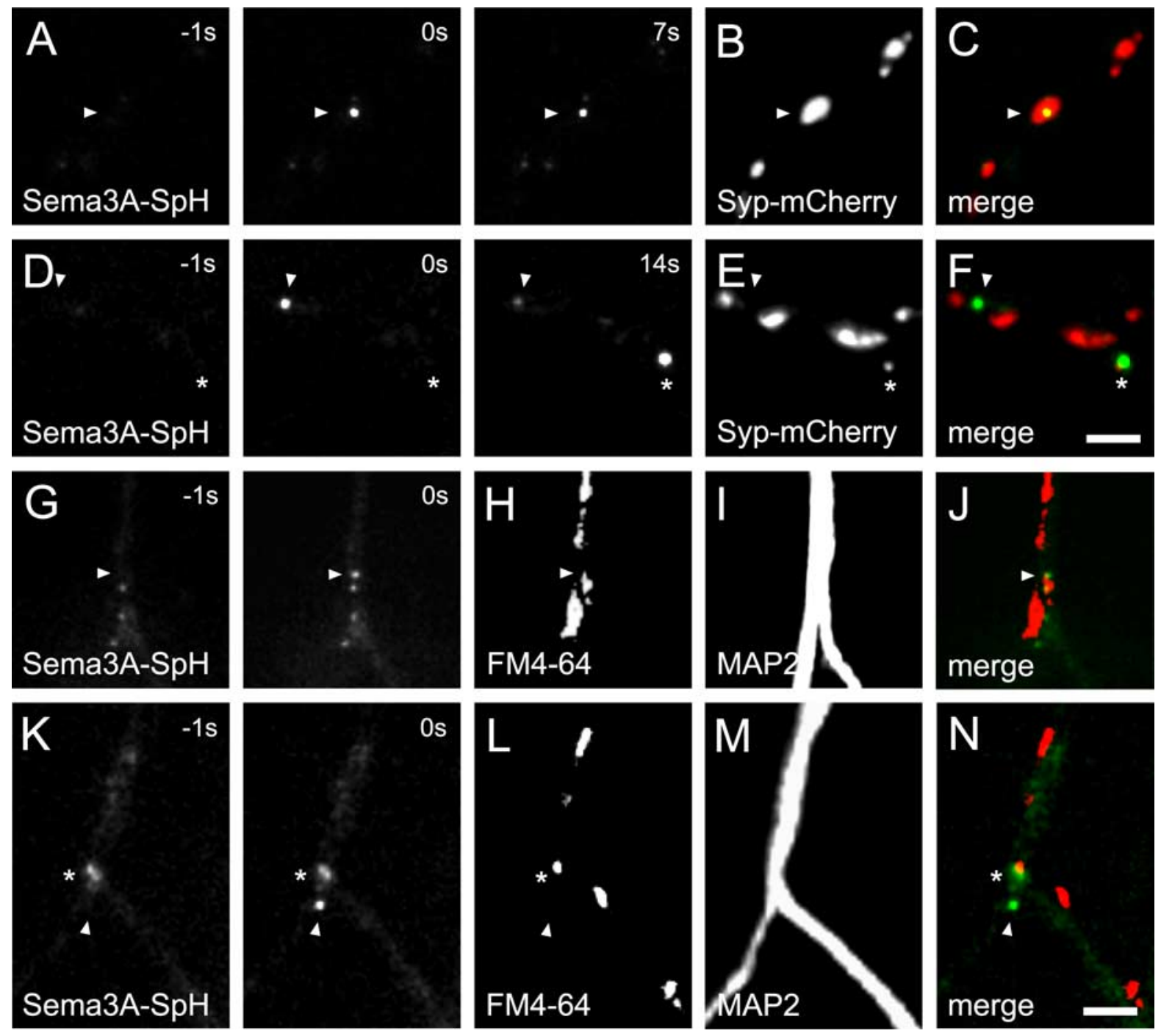

Figure 6. Synaptic and extrasynaptic SemapHluorin fusion events. $\boldsymbol{A}-\boldsymbol{F}$, Axonal SemapHluorin release. $\boldsymbol{A}$, Movie frames show a persistent SemapHluorin event (arrowheads). $\boldsymbol{B}$, Corresponding syp-mCherry signal. C, Overlay of SemapHlluorin at $t=0$ s and syp-mCherry shows synaptic localization of the SemapHluorin event. SemapHluorin fusion events were considered to be synaptic when the fluorescence center of such a fusion event lies within $200 \mathrm{~nm}$ (the approximate minimal point spread function of our system) of the synaptophysin fluorescence. $\boldsymbol{D}$, Transient SemapHluorin event (arrowheads). Note that at $t=3 \mathrm{~s}$, a second, persistent event appeared (asterisks). $\boldsymbol{E}$, Corresponding syp-mCherry signal. $\boldsymbol{F}$, Overlay of SemapHluorin at $t=3 \mathrm{~s}$ and syp-mCherry. The first SemapHluorin event (arrowhead) is extrasynaptic, and the second (asterisk) is synaptic. Only stable syp-mCherry puncta were included in the analysis. G-N, Dendritic SemapHluorin release. G, A persistent dendritic event (arrowheads). $\boldsymbol{H}$, Corresponding FM4-64 signal. I, MAP2 retrospective immunostaining. J, Overlay of SemapHluorin signal at $t=0$ s and FM4-64 signal shows that the SemapHluorin event is closely apposed to the FM4-64-labeled bouton, suggesting dendritic synaptic release. $\boldsymbol{K}-\boldsymbol{N}$, Dendritic extrasynaptic release. $\boldsymbol{K}$, A persistent dendritic event (arrowhead). $\boldsymbol{L}$, FM4-64. M, MAP2. N, Merged image of SemapHluorin at $t=0$ s and FM4-64 signal shows that the SemapHluorin event did not occur close to an FM4-64-labeled bouton, suggesting extrasynaptic release. Note that two synaptically located SemapHluorin vesicles (asterisks) did not respond to depolarization. Scale bars: $\boldsymbol{F}$ (for $\boldsymbol{A}-\boldsymbol{F}$ ), $\boldsymbol{N}($ for $\mathbf{G}-\boldsymbol{N}$ ), $2.5 \mu \mathrm{m}$.

a decay time $\tau=4.9 \pm 0.3 \mathrm{~s}$, which should represent the true diffusion kinetics of Sema3A out of the vesicle.

Together these three experiments indicate that approximately one-third of all SemapHluorin fusion events $(37-63 \%$ of the transient events; $24-40 \%$ of all events) (Fig. $4 J$ ) represent incomplete release followed by resealing/reacidification. These values are in good agreement with previous data obtained in chromaffin and PC12 cells (Holroyd et al., 2002; Perrais et al., 2004). Another third of all events (23-40\%) represents complete release followed by cargo diffusion out of the vesicle. The final third (37\%) are persistent events (Fig. 4J) (see below).

Persistent events reflect stable deposits of cargo at the cell surface

The fact that the evoked fluorescence does not decay in one-third of SemapHluorin events suggests that this cargo remains contin- uous with the extracellular space after fusion. However, resealing vesicles may not always reacidify rapidly. To test this, a brief acid wash was applied directly after stimulation. Figure $5 \mathrm{~A}$ shows three persistent events during depolarization (vesicles 2, 3, and 4). These persistent events were instantly quenched after acid wash (Fig. 5A,B), indicating that the cargo remained accessible from the exterior. The majority of all persistent events responded to acid wash $(81 \% ; n=48$ events, 10 cells). The remaining persistent events probably represent resealed but slowly acidifying vesicles. Some bright fluorescent puncta $(<5 \%)$ may not be functional secretory vesicles, but cargo in other (neutral) cellular compartments (Fig. $5 A$, vesicle 1 ).

The depolarization-evoked persistent events may either represent vesicles that became fully integrated with the plasma membrane (stable deposits) or vesicles with a permanently open fusion pore. In neuroendocrine cells, larger proteins, such as tPA or 
phogrin, remain inside fusing vesicles for $>1$ min, whereas peptides, such as NPY, or lipophilic dyes, such as FM4-64, are rapidly lost (Taraska et al., 2003; Taraska and Almers, 2004). To test this possibility, we performed live labeling with a GFP antibody, which is comparable in size to tPA or phogrin and should therefore be too large to pass through such fusion pores. SemapHluorin-expressing neurons were imaged, depolarized, live labeled, and subsequently permeabilized and processed for MAP2 immunocytochemistry. Figure $5 C$ shows a persistent event that appeared during depolarization (vesicle 2) (Fig. 5C,D). The SemapHluorin cargo in the newly appeared persistent event was live labeled with the GFP antibody (Fig. 5E). In addition, several bright vesicles that were visible before stimulation were also labeled (Fig. 5E). MAP2 staining showed that the imaged neurite was an axon (Fig. $5 E$ ). Dendritic persistent events were also live labeled (Fig. $5 F-H$ ). Note that in this case vesicle 1 , which was visible before stimulation, was not labeled (Fig. $5 H$ ). Bright vesicles visible before stimulation may (see vesicle 1 in Fig. $5 C, E$ ) or may not (see vesicle 1 in Fig. $5 A$, vesicle 1 in Fig. $5 F, H$ ) be accessible from the exterior of the cell, confirming that differences exist in acidification of secretory vesicles. Together, these data indicate that persistent release events represent stable deposits of cargo at the neuronal surface.

Stable deposits may last for minutes (e.g., Fig. 3B), but may eventually be followed by endocytosis. Occasionally, persistent events were observed that eventually started to dim and move out of the imaging region, suggesting that the vesicle underwent endocytosis and reacidification (supplemental Fig. S2 and supplemental Movie 4, available at www.jneurosci.org as supplemental material).

\section{Different types of release events occur at both synaptic and extrasynaptic sites}

Transient and persistent events occur alongside each other in one segment of a neuron (Figs. 2, 3). To test potential preferences of different types of events for specific neuronal compartments, we combined SemapHluorin imaging with dendritic and synaptic markers. First, SemapHluorin vesicles and release events localize to both axons and dendrites (Figs. 1, 5). In addition to release from neurites we also occasionally observed somatic release (data not shown). Second, SemapHluorin was coexpressed with synaptophysin-mCherry (syp-mCherry), a presynaptic marker (supplemental Fig. S3, available at www.jneurosci.org as supplemental material), and SemapHluorin events and syp-mCherry distribution were imaged simultaneously. Figure $6 \mathrm{~A}$ shows a persistent axonal SemapHluorin event that overlapped with sypmCherry fluorescence (Fig. 6B), indicating that it occurred at a presynaptic bouton (Fig. $6 C$ ). Figure $6 D$ shows a transient event (arrowheads) that did not colocalize with a syp-mCherry-labeled bouton (Fig. $6 E, F$ ), suggesting an extrasynaptic release site. Of all axonal events, $56 \pm 5 \%$ (mean \pm SEM) occurred at synaptic terminals ( $n=64$ events, 6 cells). Neither transient nor persistent events showed preference for synaptic or extrasynaptic sites on axons ( $p>0.05$; Student's $t$ test).

Third, as a complementary approach to specify the location of SemapHluorin release, neurons were loaded with the vital dye FM4-64 to label active presynaptic terminals and unloaded with a $60 \mathrm{~s}$ depolarizing stimulus. Imaged neurons were retrospectively immunostained with the dendritic marker MAP2 and carefully examined to rule out the presence of axonal SemapHluorin puncta in the imaged region. Figure $6 G-J$ shows a persistent SemapHluorin event from a MAP2-positive neurite that was closely apposed to an FM4-64-labeled bouton, suggesting that

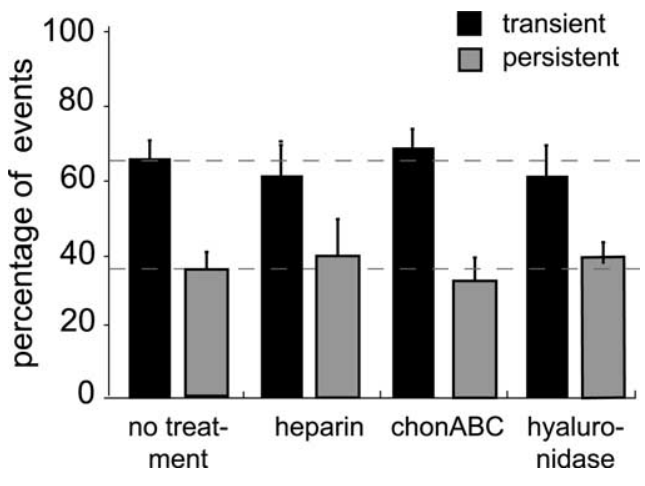

Figure 7. Ratio between transient and persistent events does not depend on the extracelIular matrix. Heparin treatment $(0.1 \mathrm{mg} / \mathrm{ml}$ for $24 \mathrm{~h}, n=58$ events, 6 cells $)$ or enzymatic reduction of the ECM by chondroitinase $A B C(0.1 \mathrm{U} / \mathrm{ml}$ for $2 \mathrm{~h}, n=65$ events, 7 cells $)$ or hyaluronidase ( $500 \mu \mathrm{U} / \mathrm{ml}$ for $18 \mathrm{~h}, n=53$ events, 10 cells) does not affect the ratio between transient and persistent events (transient vs persistent events \pm SEM for no treatment: $63.6 \pm$ $5.1 \%$ vs $38.2 \pm 4.2 \%$; heparin: $60.3 \pm 10.2 \%$ vs $39.7 \pm 8.1 \%$; chonABC: $65.8 \pm 9.3 \%$ vs $35.1 \pm 7.3 \%$; hyaluronidase: $59.8 \pm 8.7 \%$ vs $39.8 \pm 6.8 \%$ )

the release event occurred from a postsynaptic location. Like axonal release events, dendritic events were also observed at extrasynaptic locations (Fig. $6 K-N$, arrowheads). Interestingly, two synaptically located SemapHluorin puncta in the same field of view did not respond to the depolarizing stimulus (Fig. $6 \mathrm{~K}-\mathrm{N}$, asterisks). In line with axonal release, $52 \pm 9 \%$ of all dendritic events occurred at synaptic locations ( $n=58$ events, 4 cells). There was no significant preference for transient or persistent events at either location ( $p>0.05$; Student's $t$ test). The average synapse density on a dendritic arbor in our culture system is 0.15 synapse/ $\mu \mathrm{m}$ dendrite, with an average synapse size of $1 \mu \mathrm{m}$ (data not shown). Without taking dendritic volume in consideration, a random overlap of SemapHluorin events with synaptic sites would then be $15 \%$. The $52 \%$ synaptic release that we observe suggests that secretory granules are actively recruited to synaptic sites, in line with reports from Drosophila (Shakiryanova et al., 2006). Thus, transient and persistent SemapHluorin events occur at synaptic as well as extrasynaptic sites, indicating that fusogenic SNARE complexes exist extrasynaptically.

\section{Ratio between transient and persistent events does not depend on the extracellular matrix}

Secreted Sema3A binds to the extracellular matrix (ECM) (De Wit et al., 2005), which could function to attract or trap secreted SemapHluorin and explain the occurrence of stable deposits. To test this, we first tested whether excess glycosaminoglycans could interfere with Sema3A binding to the ECM. Application of heparin $(0.1 \mathrm{mg} / \mathrm{ml})$ to neuronal cultures $24 \mathrm{~h}$ before imaging efficiently competed with Sema3A for binding to the ECM, removing the characteristic Sema3A halo surrounding transfected neurons (data not shown). However, heparin treatment did not affect the ratio between transient and persistent events (Fig. 7). Next, we degraded essential components of the ECM using hyaluronidase $(500 \mu \mathrm{U} / \mathrm{ml})$ and chondroitinase $\mathrm{ABC}(0.1 \mathrm{U} / \mathrm{ml})$ treatment for 24 and $2 \mathrm{~h}$ before imaging, respectively. Both enzymes efficiently removed secreted Sema3A bound to glial cells but did not affect the release mode (Fig. 7). Thus, secreted Sema3A binds to ECM components in cortical neurons, but this interaction does not affect the release characteristics of Sema3A.

Ratio between transient or persistent events is cargo specific To determine whether the observed transient and persistent SemapHluorin fusion modes are a general feature of secretory 

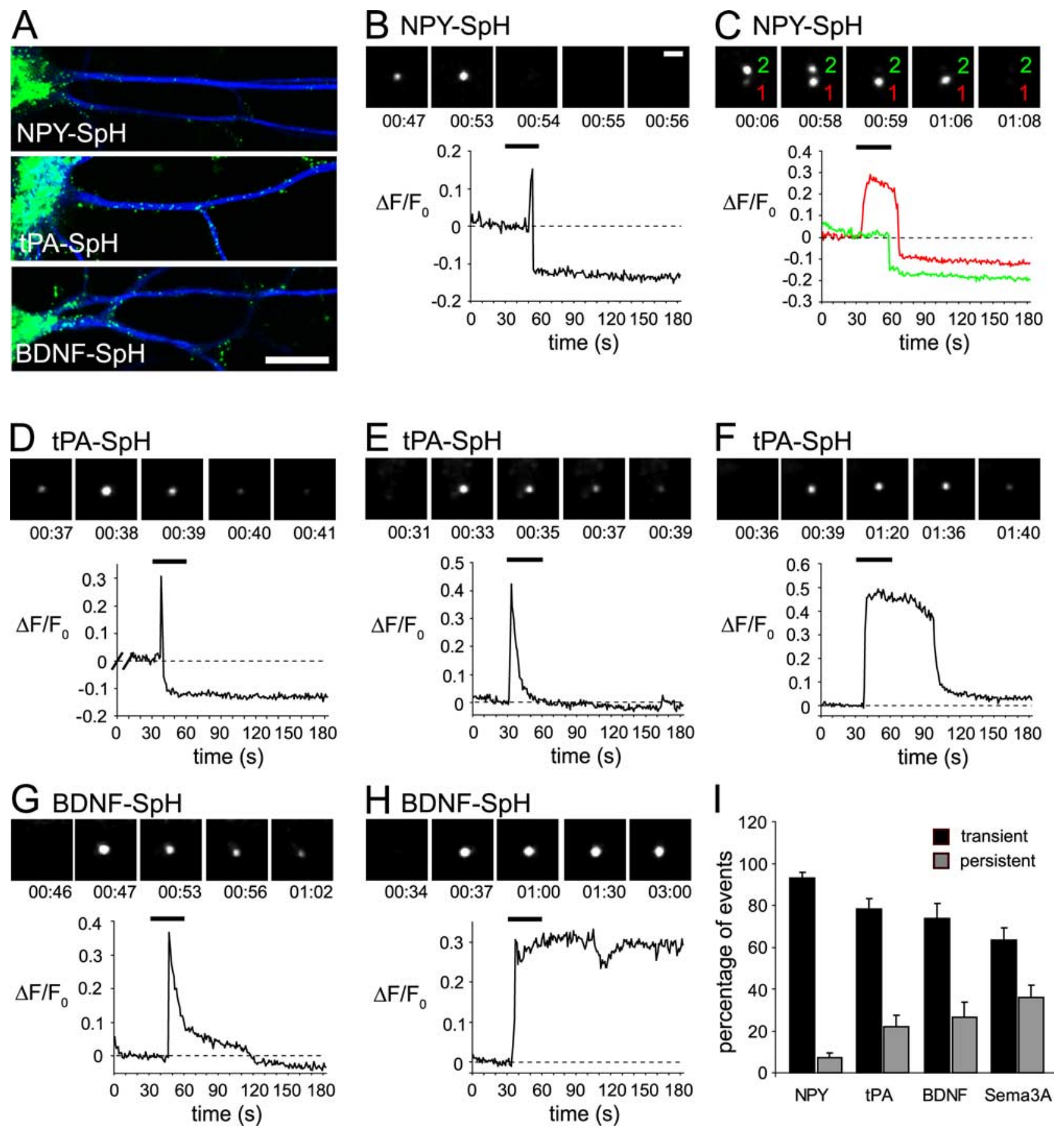

Figure 8. The balance between transient and persistent fusion events depends on cargo type. $A$, Punctate distribution of NPY-SpH, tPA-SpH, and BDNF-SpH (green) in MAP2-labeled dendrites (blue) of cortical neurons. $\boldsymbol{B}$, Movie frames and corresponding fluorescence $\left(\Delta F / F_{0}\right)$ of a representative transient NPY-SpH event. NPY-SpH vesicles emptied too fast to be well resolved with 1 frame/s imaging rate. C, NPY-SpH vesicle showed a prolonged increased fluorescence before disappearing (vesicle 1). A second vesicle abruptly disappeared after $\mathrm{K}^{+}$(vesicle 2). D, Transiently brightening tPA-SpH vesicle. Faint fluorescence remained at the fusion site, suggesting that the vesicle had not completely emptied. The first $10 \mathrm{~s}$ of trace are not shown because of vesicle movement. $\boldsymbol{E}$, Transient tPA-SpH event. $\boldsymbol{F}$, Persistent tPA-SpH event. The fluorescence of the vesicle eventually dimmed again and remained faintly visible at the fusion site, suggesting that the vesicle had reacidified. $\boldsymbol{G}$, Transient BDNF-SpH event. $\boldsymbol{H}$, Persistent BDNF-SpH event. Black bars indicate duration of $\mathrm{K}^{+}$stimulus. $\boldsymbol{I}$, Graph showing percentage of transient (black bars) and persistent (gray bars) events for NPY-SpH, tPA-SpH, BDNF-SpH, and SemapHluorin vesicles. Scale bars: $\boldsymbol{A}, 10 \mu \mathrm{m}$; (in $\boldsymbol{B}) \boldsymbol{B}-\boldsymbol{H}, 1 \mu \mathrm{m}$.

granule release in neurons, we analyzed secretion of NPY, tPA, and BDNF. When coexpressed, Sema3A localizes to the same vesicles as NPY or tPA (de Wit et al., 2006) and BDNF (data not shown). SpH-tagged NPY, BDNF, and tPA showed a punctate localization in dendrites (Fig. 8A) and axons (data not shown). $\mathrm{NPY}-\mathrm{SpH}$ is a relatively small protein $(\sim 34-42 \mathrm{kDa}$ including $\mathrm{SpH}$ tag and depending on the degree of processing) compared with SemapHluorin ( $\sim 90-130 \mathrm{kDa}$ depending on processing). Imaging of NPY-SpH release revealed marked differences with SemapHluorin release. Figure $8 B$ shows a representative NPY$\mathrm{SpH}$ vesicle that transiently brightened before rapidly disappearing, suggesting that the vesicle had emptied. The majority of NPY-SpH vesicles abruptly disappeared after depolarization $(93 \pm 3 \%$; mean \pm SEM; $n=69$ events, 7 cells) (Fig. $8 I$ ). In rare 
cases, NPY-SpH vesicles remained bright for a prolonged period of time before suddenly disappearing (vesicle 1) (Fig. 8C). The sparse occurrence of NPY-SpH persistent events ( $7 \pm 3 \%$ of total events) was in marked contrast to the incidence of SemapHluorin persistent events (36 $\pm 6 \%$ of total events) (Fig. $8 I$ ).

We compared release of NPY and Sema3A with tPA-SpH (97 $\mathrm{kDa}$ ), which leaves secretory granules more slowly than NPY in chromaffin cells (Perrais et al., 2004). Interestingly, tPA-SpH fusion events showed characteristics of both NPY and Sema3A release and were similar to the events observed in chromaffin cells (Perrais et al., 2004). Transiently brightening and abruptly disappearing vesicles, as observed for NPY, were also observed for tPA (Fig. $8 D$ ). In addition, transient events occurred that were characterized by an abrupt increase in fluorescence and a rapid decay of fluorescence back to baseline levels, reminiscent of SemapHluorin transient events (Fig. $8 E$ ). Figure $8 F$ shows an example of a persistent tPA-SpH event, followed by gradual reacidification of the vesicle. Persistent events accounted for $22 \pm 5 \%$ of total tPA-SpH fusion events ( $n=93$ events, 8 cells) (Fig. $8 I$ ).

The difference in ratio between transient and persistent events for NPY and tPA suggests that the molecular weight of the vesicle cargo determines the nature of fusion events after stimulus. Interestingly however, the fusion characteristics of BDNF-SpH (a protein similar in size to NPY-SpH with an estimated molecular weight of $58-43 \mathrm{kDa}$ depending on the degree of processing) more closely resembled those of Sema3A than those of NPY (Fig. $8 G, H)$. Persistent events constituted $26.5 \pm 7.2 \%$ of the total number of BDNF-SpH events ( $n=102$ events, 7 cells) (Fig. $8 I$ ). Thus, although BDNF-SpH is similar in size to NPY, the fusion characteristics of BDNF are comparable to those of larger cargo proteins, suggesting that cargo protein-specific properties affect the balance between transient and persistent fusion events.

\section{Stable deposits depend on the interaction between Sema3A and the vesicle lumen}

Condensed vesicle cargo is packed inside secretory vesicles and interacts with charged luminal (glyco)proteins via polybasic domains (Kelly, 1985; Arvan and Castle, 1998). Sema3A contains such a basic domain at its C terminus (Luo et al., 1993). To test the importance of the interaction between cargo and vesicle matrix, we expressed a SemapHluorin construct lacking the basic domain (Sema $\Delta B D$ ) in cortical neurons. Sema $\Delta B D$ was sorted to secretory vesicles, and $\mathrm{NH}_{4} \mathrm{Cl}$ application resulted in a marked increase in the fluorescence per vesicle and the number of visible vesicles (Fig. 9A-C). Electrical stimulation resulted in secretory vesicle release similar to full-length SemapHluorin. However, the mode of release was now strongly shifted toward transient release (transient events: $84.2 \pm 7.9 \%$, persistent events: $5.8 \pm 5.2 \%$; mean \pm SEM, $n=69$ events, 12 cells). Hence, the interaction of Sema3A with luminal (glyco)proteins via its basic domain is an important determinant of the release mode and explains the occurrence of stable Sema3A deposits at the plasma membrane.

Corelease of Sema3A alters the release characteristics of NPY Because the interaction of Sema3A with the luminal matrix can explain the occurrence of stable deposits, this interaction may also be able to trap other secreted molecules as stable deposits at the plasma membrane. To test whether Sema3A is capable of confining cosecreted molecules at the fusion site, we coexpressed Sema3A-mRFP with NPY-SpH. In neurons coexpressing Sema3A-mRFP and NPY-SpH, the majority of secretory vesicles contained both proteins (Fig. 10B). If Sema3A is able to trap cosecreted NPY, the characteristic transient fusion mode of NPY
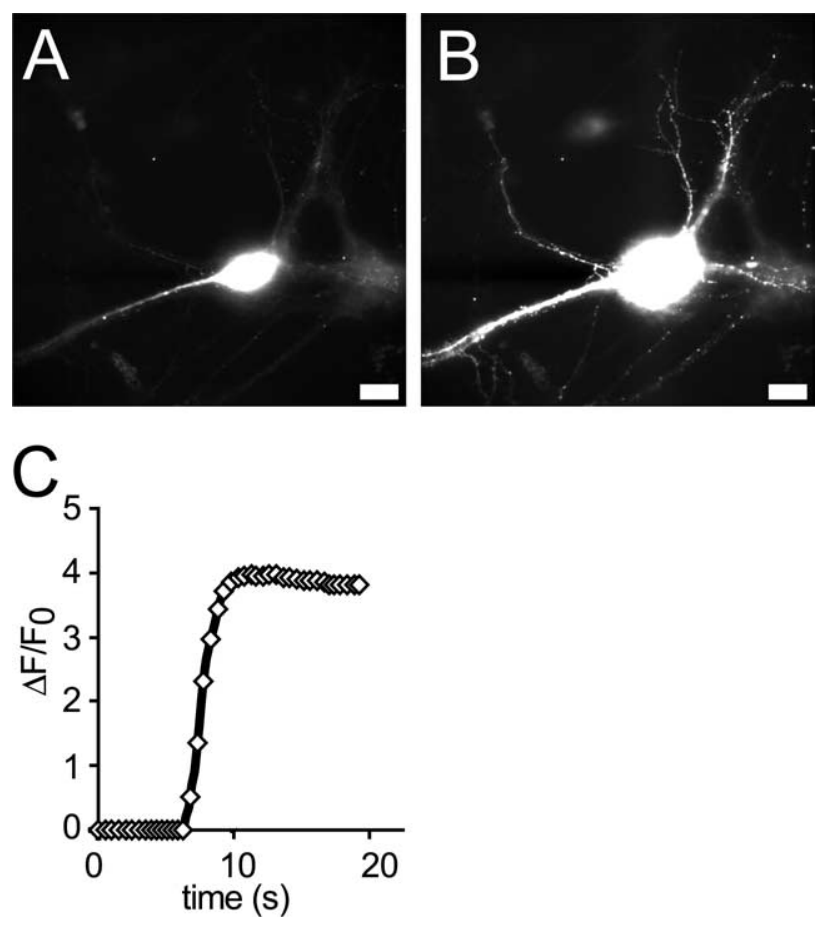

Figure 9. Stable deposits depend on the interaction between Sema3A and the vesicle lumen. $\boldsymbol{A}, \boldsymbol{B}$, Cortical neuron expressing SemapHluorin without the C-terminal basic domain (Sema $\Delta B D$ ) before $(\boldsymbol{A})$ and after $(\boldsymbol{B}) \mathrm{NH}_{4} \mathrm{Cl}$ application. Like full-length SemapHluorin, Sema $\Delta B D$ is targeted to acidic secretory vesicles, and $\mathrm{NH}_{4} \mathrm{Cl}$ application reveals numerous bright secretory vesicles. Note the complete absence of Sema $\triangle B D$ binding to supporting glial cells. $\boldsymbol{C}$, The fourfold average vesicular fluorescence increase after $\mathrm{NH}_{4} \mathrm{Cl}$ application is similar to full-length SemapHluorin. Scale bars, $5 \mu \mathrm{m}$.

should change to a more persistent mode. Indeed, coexpression of Sema3A-mRFP and NPY-SpH resulted in a dramatic, significant increase in the percentage of persistent NPY-SpH events (Fig. 10A) as well as the duration of NPY-SpH release events (Fig. $10 C$ ), whereas the number of events per cell was unaffected (Fig. $10 D)$. This suggests that corelease of Sema3A confines diffusible NPY molecules in stable deposits at the cell surface. To test whether this phenotype is specific for Sema3A, we coexpressed NPY-SpH with BDNF-mRFP or tPA-mRFP. Coexpression of these molecules did not affect the release characteristics of NPY$\mathrm{SpH}$ (Fig. 10 A, C). Thus, Sema3A released from secretory vesicles could function as crystallization point for the formation of signaling microdomains at the cell membrane.

\section{Discussion}

In neurons, secretory granules mediate the regulated secretion of a diverse array of proteins with important roles in neuronal development and plasticity. Here, we characterized the different ways in which such cargo is secreted. In addition to transient events, which were previously observed in endocrine cells and represent either full release followed by cargo diffusion or incomplete release followed by vesicle retrieval, we also observed that certain cargo was delivered at the cell surface as stable deposits, depending on cargo type and interactions with the luminal matrix.

Transient release events in neurons are similar to release events in endocrine cells

Secretory granule exocytosis in neurons often appeared as bright fluorescent flashes along axons and dendrites, as the efflux of 

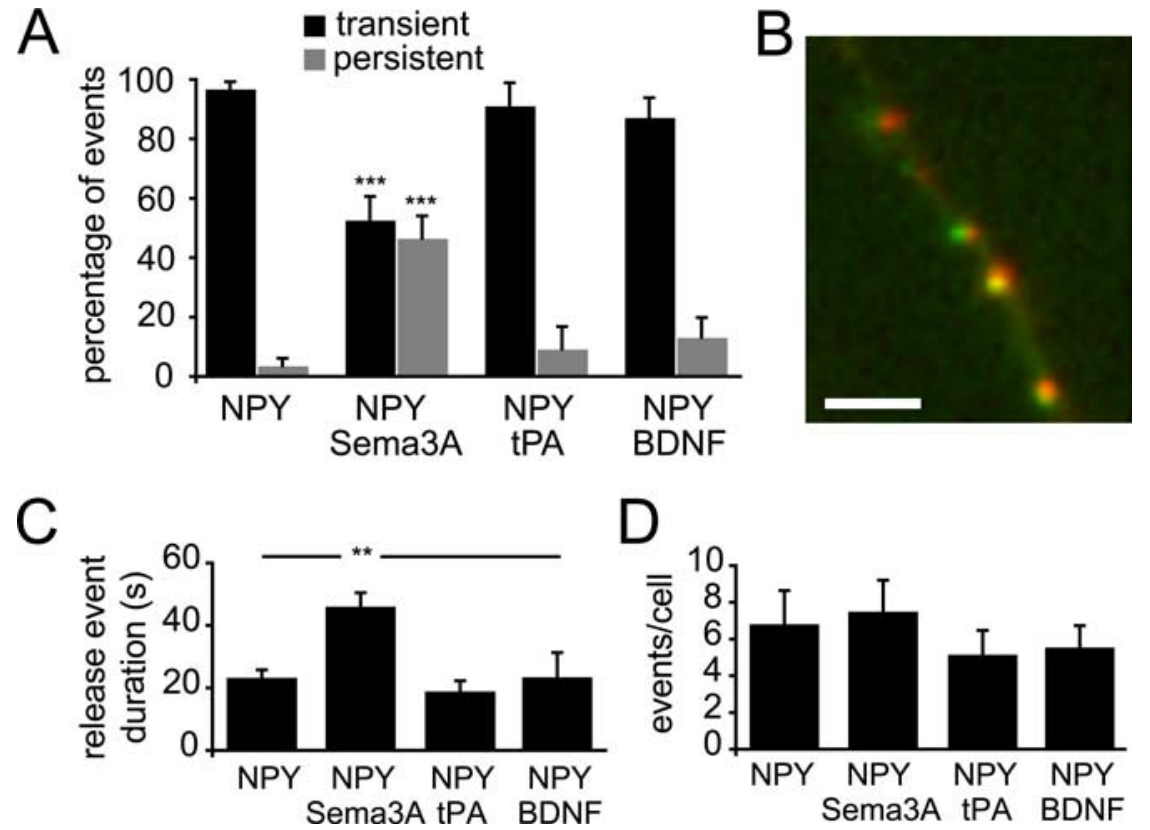

Figure 10. Sema3A changes the release characteristics of coexpressed NPY. A, Graph showing percentage of transient (black bars) and persistent (gray bars) events after $50 \mathrm{~Hz}$ stimulation for NPY-SpH vesicles. Coexpression of Sema3A-mRFP but not tPA-mRFP or BDNF-mRFP changes NPY-SpH fusion mode from predominantly transient $(96.6 \pm 2.4 \%$ transient, $3.4 \pm 2.4 \%$ persistent, mean $\pm \mathrm{SEM}, n=109$ events, 16 cells) to almost evenly transient and persistent (52.4 $\pm 8 \%$ transient, $46.3 \pm 8 \%$ persistent, $n=75$ events, 10 cells, ${ }^{* *} p<0.001$ ) events. Coexpression of tPA-mRFP or BDNF-mRFP did not change this ratio (91 $\pm 7.7 \%$ transient, $n=36$ events, 7 cells and $87 \pm 6.7 \%$ transient, $n=61$ events, 11 cells, respectively). B, Sema3A-mRFP (red) and NPY-SpH (green) colocalize in secretory vesicles after coexpression in cortical neurons. Green and red channels were imaged with a 1 sinterval, causing a small shift in alignment as a result of vesicle movement. $\mathbf{C}$, Graph showing average duration of all release events in neurons expressing NPY-SpH alone or together with Sema3A-mRFP, tPA-mRFP, or BDNF-mRFP. Coexpression of Sema3A-mRFP increases the average duration of all events from $23.1 \pm 2.4 \mathrm{~s}$ to $46.0 \pm 4.2 \mathrm{~s}\left({ }^{* *} p<0.01\right)$. Coexpression of tPA-mRFP or BDNF-mRFP did not change the average duration (18.8 \pm 3.3 s and $23.4 \pm 7.6 \mathrm{~s}$, respectively). $D$, Graph showing average number of release events per cell. Coexpression of Sema3A-mRFP, tPA-mRFP, or BDNF-mRFP did not change the number of NPY-SpH events per cell. Scale bar, $5 \mu \mathrm{m}$.

protons relieved quenching of $\mathrm{SpH}$-tagged cargo. The subsequent gradual loss of fluorescence was attributable to two distinct phenomena: (1) diffusion of cargo protein out of the vesicle and (2) retrieval of vesicles after incomplete release, followed by reacidification. Similar release characteristics were previously observed in chromaffin, insulin-secreting, and PC12 cells (Tsuboi et al., 2000; Holroyd et al., 2002; Taraska et al., 2003; Perrais et al., 2004). Perrais et al. (2004) used the terms "discharge" and "display" to discriminate between full fusion and incomplete release during transient fusion pore opening. It is important to note that the stable deposits reported here differ from these "display" events. For cargo favoring stable deposits, such as Sema3A and BDNF, we also observed both "display" (transient opening) and "discharge" (classical release) events, in addition to stable deposits. Stable deposits also occurred at locations of previous incomplete release events (e.g., vesicle 2 in Fig. 2), suggesting that a transient opening preceded the subsequent full fusion of single vesicles.

In chromaffin cells, release of catecholamines and small neuropeptides such as NPY is very fast (Wightman et al., 1991; Perrais et al., 2004). In neurons, we observed similar fast NPY release. For tPA, slower release kinetics were more frequently observed (Fig. 8). These findings are consistent with the idea that cargo size influences the ratio between complete and incomplete release events (Perrais et al., 2004). However, cargo size is not a likely explanation for differences between transient events (both complete and incomplete release) and stable deposits (see below).
Compared with the fast kinetics of NPY and $\mathrm{TPA}$, release of BDNF and Sema3A was slow. Transient Sema3A events, as well as BDNF transient events (data not shown), were slow enough to be quenched by acid wash. Probably, interactions between such cargo and the luminal matrix prevent faster kinetics (see below), as previously suggested for the slow release of BDNF in synapses (Brigadski et al., 2005).

Transient release events evoked by electrical stimulation had a lower time constant than those evoked by $\mathrm{K}^{+}$stimulation, and approached the time constant in bafilomycin-treated cells. This suggests that in cells stimulated at a high frequency, a larger proportion of transient events represent classical release than retrieval. Hence, stimulation patterns may modulate the ratio between complete and incomplete release and thus the amount of cargo released (Balkowiec and Katz, 2000; Gärtner and Staiger, 2002).

Cargo-specific properties determine the ratio between transient events and stable deposits

Persistent events accounted for a large proportion of Sema3A, BDNF, and tPA release events. The sensitivity of these events to acid wash indicates that deposited cargo remained exposed to the extracellular space. Therefore, we concluded that these events represent stable, local deposits of vesicle cargo at the cell surface. Alternatively, these events may be explained by assuming that the fusion pore remained open for minutes. It has been observed that transient ("display") events can last for tens of seconds (Perrais et al., 2004). However, the duration of the events in our study was even longer, sometimes existing for as long as recordings lasted (2 $\mathrm{min}$ ). Moreover, the $\mathrm{SpH}$-tagged cargo in these stable deposits was readily accessible for live labeling with a GFP antibody, making prolonged fusion pore openings an unlikely explanation. Hence, stable deposits are distinct from previously observed classical fusion and transient fusion pore openings, and may be neuron specific. One exception could be the prolonged extracellular association of FM-dye-binding cargo clusters in lactotrophs (Angleson et al., 1999). However, it seems most plausible that this cargo (prolactin) still needs to diffuse away to exert its biological function, in contrast to neuronspecific cargo such as neurotrophins and guidance cues (see below). Persistent events have also been observed in pancreatic $\beta$-cells, but resulted from the sequence of amino acids linking the cargo to the fluorescent reporter (Michael et al., 2004). The stable deposits we observe are unlikely to result from fluorescent protein tagging, because we used linkerless constructs.

We found no evidence for differences in the secretion machinery to explain the differences between transient events and stable deposits. All events were $\mathrm{Ca}^{2+}$ and SNARE dependent. Second, we found no preference for either type of event at synaptic or extrasynaptic locations. Third, although certain cargo types bind to the ECM (De Wit et al., 2005), ECM manipulations did not alter the ratio between transient and stable events. Fourth, differ- 
ences between transient events and stable deposits were not explained by cargo size. Cargo size is a likely explanation for differences among transient events (see above and Perrais et al., 2004). However, although BDNF-SpH and NPY-SpH have comparable molecular weights, their release was strikingly different, with BDNF favoring stable deposits. Hence, the differences between transient events and stable deposits appear to be primarily determined by specific physicochemical cargo properties.

One specific property of the cargo types that give rise to stable deposits is their ability to interact with the granule matrix. BDNF and Sema3A are highly basic molecules (Barde et al., 1982; Luo et al., 1993), which probably interact with the proteoglycan components of the granule matrix (Kolset et al., 2004). Indeed, deletion of the basic domain of Sema3A abolished stable deposits. We conclude that the interactions between cargo and vesicle matrix components are preserved after integration of the vesicle into the plasma membrane to serve as focal signaling domains on the cell surface. The fluorescent intensity of stable deposits is surprisingly stable over the duration of recordings, suggesting that local capture is very efficient and that escape of Sema3A or BDNF from these deposits is minimal. The idea of local capture of signaling components by former secretory vesicle constituents was further strengthened after the coaccumulation of Sema3A and NPY in single vesicles. This changed the NPY release characteristics from transient events to the persistent events typical of cargo that interacts with the vesicle lumen, suggesting that corelease of Sema3A confines diffusible NPY molecules in stable deposits at the cell surface.

\section{Stable deposit of cargo is consistent with biological function}

The fact that regulated exocytosis of secretory vesicles containing Sema3A or BDNF generates local, stable deposits on the neuronal surface is consistent with the known cellular functions of these cargo types, e.g., guidance of processes and synapse formation/ remodeling, which require highly localized signaling (Horch and Katz, 2002; Zhang and Poo, 2002; Sahay et al., 2005; Bouzioukh et al., 2006; Morita et al., 2006). Local accumulation of Sema3A on the neuronal surface has been observed for the endogenous protein (Eastwood et al., 2003; Good et al., 2004). The stable deposits reported here may also be related to the lingering extracellular presence of secreted BDNF (Brigadski et al., 2005) and the protease neurotrypsin (Frischknecht et al., 2008) in synapses. In these cases release was strictly synaptic and the extracellular presence may therefore be attributable to interactions with the ECM, which is concentrated at synapses (John et al., 2006).

Each of the cargo types studied here was released by a combination of stable and transient events. The degree of cargo association with the granule matrix could vary between vesicles. Alkalinization solubilizes the granule matrix (Han et al., 1999), and this accelerates release (Brigadski et al., 2005). However, the intensity of transient and stable SemapHluorin events before fusion did not differ significantly (data not shown), suggesting that variations in intravesicular $\mathrm{pH}$ do not determine the release mode. Variations in the degree of cargo protein processing could affect release characteristics. Proteolytic processing of Sema3A generates a fragment that lacks the basic domain (Adams et al., 1997), which would favor transient events. It is also conceivable that intracellular second messengers influence the release mode: elevated calcium concentrations shift the preferred fusion mode in chromaffin cells (Alés et al., 1999), and cAMP levels influence cargo solubilization and thereby release characteristics in lactotrophs (Angleson et al., 1999).

\section{Release events occurred surprisingly often at extrasynaptic sites}

A surprisingly large proportion of release events, $\sim 50 \%$, occurred at extrasynaptic locations on axons and dendrites. Fusing secretory vesicles outside synapses have previously been observed in dendrites using electron microscopy (Zhu et al., 1986) and live imaging (Hartmann et al., 2001), and from the somata of substantia nigra neurons using amperometry (Jaffe et al., 1998). Although overexpression of cargo may influence the synaptic/extrasynaptic ratio, these data confirm that secretory granule release does not require a specialized active zone and that fusogenic SNARE complexes exist outside synapses.

\section{References}

Adams RH, Lohrum M, Klostermann A, Betz H, Püschel AW (1997) The chemorepulsive activity of secreted semaphorins is regulated by furindependent proteolytic processing. EMBO J 16:6077-6086.

Alés E, Tabares L, Poyato JM, Valero V, Lindau M, Alvarez de Toledo G (1999) High calcium concentrations shift the mode of exocytosis to the kiss-and-run mechanism. Nat Cell Biol 1:40-44.

An S, Zenisek D (2004) Regulation of exocytosis in neurons and neuroendocrine cells. Curr Opin Neurobiol 14:522-530.

Angleson JK, Cochilla AJ, Kilic G, Nussinovitch I, Betz WJ (1999) Regulation of dense core release from neuroendocrine cells revealed by imaging single exocytic events. Nat Neurosci 2:440-446.

Artalejo CR, Elhamdani A, Palfrey HC (1998) Secretion: dense-core vesicles can kiss-and-run too. Curr Biol 8:R62-R65.

Arvan P, Castle D (1998) Sorting and storage during secretory granule biogenesis: looking backward and looking forward. Biochem J 332:593-610.

Ashby MC, Ibaraki K, Henley JM (2004) It's green outside: tracking cell surface proteins with pH-sensitive GFP. Trends Neurosci 27:257-261.

Aspinwall CA, Brooks SA, Kennedy RT, Lakey JR (1997) Effects of intravesicular $\mathrm{H}+$ and extracellular $\mathrm{H}+$ and $\mathrm{Zn} 2+$ on insulin secretion in pancreatic beta cells. J Biol Chem 272:31308-31314.

Balkowiec A, Katz DM (2000) Activity-dependent release of endogenous brain-derived neurotrophic factor from primary sensory neurons detected by ELISA in situ. J Neurosci 20:7417-7423.

Barde YA, Edgar D, Thoenen H (1982) Purification of a new neurotrophic factor from mammalian brain. EMBO J 1:549-553.

Basham ME, Seeds NW (2001) Plasminogen expression in the neonatal and adult mouse brain. J Neurochem 77:318-325.

Bouzioukh F, Daoudal G, Falk J, Debanne D, Rougon G, Castellani V (2006) Semaphorin3A regulates synaptic function of differentiated hippocampal neurons. Eur J Neurosci 23:2247-2254.

Brigadski T, Hartmann M, Lessmann V (2005) Differential vesicular targeting and time course of synaptic secretion of the mammalian neurotrophins. J Neurosci 25:7601-7614.

De Wit J, De Winter F, Klooster J, Verhaagen J (2005) Semaphorin 3A displays a punctate distribution on the surface of neuronal cells and interacts with proteoglycans in the extracellular matrix. Mol Cell Neurosci 29:40-55.

de Wit J, Toonen RF, Verhaagen J, Verhage M (2006) Vesicular trafficking of semaphorin $3 \mathrm{~A}$ is activity-dependent and differs between axons and dendrites. Traffic 7:1060-1077.

Dröse S, Altendorf K (1997) Bafilomycins and concanamycins as inhibitors of V-ATPases and P-ATPases. J Exp Biol 200:1-8.

Eastwood SL, Law AJ, Everall IP, Harrison PJ (2003) The axonal chemorepellant semaphorin $3 \mathrm{~A}$ is increased in the cerebellum in schizophrenia and may contribute to its synaptic pathology. Mol Psychiatry 8:148-155.

Frischknecht R, Fejtova A, Viesti M, Stephan A, Sonderegger P (2008) Activity-induced synaptic capture and exocytosis of the neuronal serine protease neurotrypsin. J Neurosci 28:1568-1579.

Gärtner A, Staiger V (2002) Neurotrophin secretion from hippocampal neurons evoked by long-term-potentiation-inducing electrical stimulation patterns. Proc Natl Acad Sci U S A 99:6386-6391.

Giger RJ, Wolfer DP, De Wit GM, Verhaagen J (1996) Anatomy of rat semaphorin III/collapsin-1 mRNA expression and relationship to developing nerve tracts during neuroembryogenesis. J Comp Neurol 375:378-392.

Good PF, Alapat D, Hsu A, Chu C, Perl D, Wen X, Burstein DE, Kohtz DS (2004) A role for semaphorin 3A signaling in the degeneration of hippocampal neurons during Alzheimer's disease. J Neurochem 91:716-736. 
Han W, Li D, Stout AK, Takimoto K, Levitan ES (1999) $\mathrm{Ca}^{2+}$-induced deprotonation of peptide hormones inside secretory vesicles in preparation for release. J Neurosci 19:900-905.

Hartmann M, Heumann R, Lessmann V (2001) Synaptic secretion of BDNF after high-frequency stimulation of glutamatergic synapses. EMBO J 20:5887-5897.

Haubensak W, Narz F, Heumann R, Lessmann V (1998) BDNF-GFP containing secretory granules are localized in the vicinity of synaptic junctions of cultured cortical neurons. J Cell Sci 111:1483-1493.

Higuchi H, Yang HY, Sabol SL (1988) Rat neuropeptide Y precursor gene expression. mRNA structure, tissue distribution, and regulation by glucocorticoids, cyclic AMP, and phorbol ester. J Biol Chem 263:6288-6295.

Hofer M, Pagliusi SR, Hohn A, Leibrock J, Barde YA (1990) Regional distribution of brain-derived neurotrophic factor mRNA in the adult mouse brain. EMBO J 9:2459-2464.

Holroyd P, Lang T, Wenzel D, De Camilli P, Jahn R (2002) Imaging direct, dynamin-dependent recapture of fusing secretory granules on plasma membrane lawns from PC12 cells. Proc Natl Acad Sci USA 99:16806-16811.

Horch HW, Katz LC (2002) BDNF release from single cells elicits local dendritic growth in nearby neurons. Nat Neurosci 5:1177-1184.

Jaffe EH, Marty A, Schulte A, Chow RH (1998) Extrasynaptic vesicular transmitter release from the somata of substantia nigra neurons in rat midbrain slices. J Neurosci 18:3548-3553.

John N, Krügel H, Frischknecht R, Smalla KH, Schultz C, Kreutz MR, Gundelfinger ED, Seidenbecher CI (2006) Brevican-containing perineuronal nets of extracellular matrix in dissociated hippocampal primary cultures. Mol Cell Neurosci 31:774-784.

Kelly RB (1985) Pathways of protein secretion in eukaryotes. Science 230:25-32.

Köhrmann M, Haubensak W, Hemraj I, Kaether C, Lessmann VJ, Kiebler MA (1999) Fast, convenient, and effective method to transiently transfect primary hippocampal neurons. J Neurosci Res 58:831-835.

Kolset SO, Prydz K, Pejler G (2004) Intracellular proteoglycans. Biochem J 379:217-227.

Lindau M, Almers W (1995) Structure and function of fusion pores in exocytosis and ectoplasmic membrane fusion. Curr Opin Cell Biol 7:509-517.

Luo Y, Raible D, Raper JA (1993) Collapsin: a protein in brain that induces the collapse and paralysis of neuronal growth cones. Cell 75:217-227.

McAllister AK, Katz LC, Lo DC (1999) Neurotrophins and synaptic plasticity. Annu Rev Neurosci 22:295-318.

Michael DJ, Geng X, Cawley NX, Loh YP, Rhodes CJ, Drain P, Chow RH (2004) Fluorescent cargo proteins in pancreatic beta-cells: design determines secretion kinetics at exocytosis. Biophys J 87:L03-L05.

Miesenböck G, De Angelis DA, Rothman JE (1998) Visualizing secretion and synaptic transmission with $\mathrm{pH}$-sensitive green fluorescent proteins. Nature 394:192-195.

Morita A, Yamashita N, Sasaki Y, Uchida Y, Nakajima O, Nakamura F, Yagi T,
Taniguchi M, Usui H, Katoh-Semba R, Takei K, Goshima Y (2006) Regulation of dendritic branching and spine maturation by semaphorin3AFyn signaling. J Neurosci 26:2971-2980.

Pang PT, Lu B (2004) Regulation of late-phase LTP and long-term memory in normal and aging hippocampus: role of secreted proteins tPA and BDNF. Ageing Res Rev 3:407-430.

Parmer RJ, Mahata M, Mahata S, Sebald MT, O’Connor DT, Miles LA (1997) Tissue plasminogen activator (t-PA) is targeted to the regulated secretory pathway. Catecholamine storage vesicles as a reservoir for the rapid release of t-PA. J Biol Chem 272:1976-1982.

Perrais D, Kleppe IC, Taraska JW, Almers W (2004) Recapture after exocytosis causes differential retention of protein in granules of bovine chromaffin cells. J Physiol 560:413-428.

Sahay A, Kim CH, Sepkuty JP, Cho E, Huganir RL, Ginty DD, Kolodkin AL (2005) Secreted semaphorins modulate synaptic transmission in the adult hippocampus. J Neurosci 25:3613-3620.

Sankaranarayanan S, Ryan TA (2001) Calcium accelerates endocytosis of vSNAREs at hippocampal synapses. Nat Neurosci 4:129-136.

Sankaranarayanan S, De Angelis D, Rothman JE, Ryan TA (2000) The use of pHluorins for optical measurements of presynaptic activity. Biophys J 79:2199-2208.

Scalettar BA (2006) How neurosecretory vesicles release their cargo. Neuroscientist 12:164-176.

Shakiryanova D, Tully A, Levitan ES (2006) Activity-dependent synaptic capture of transiting peptidergic vesicles. Nat Neurosci 9:896-900.

Silverman MA, Johnson S, Gurkins D, Farmer M, Lochner JE, Rosa P, Scalettar BA (2005) Mechanisms of transport and exocytosis of dense-core granules containing tissue plasminogen activator in developing hippocampal neurons. J Neurosci 25:3095-3106.

Taraska JW, Almers W (2004) Bilayers merge even when exocytosis is transient. Proc Natl Acad Sci U S A 101:8780-8785.

Taraska JW, Perrais D, Ohara-Imaizumi M, Nagamatsu S, Almers W (2003) Secretory granules are recaptured largely intact after stimulated exocytosis in cultured endocrine cells. Proc Natl Acad Sci U S A 100:2070-2075.

Tsuboi T, Zhao C, Terakawa S, Rutter GA (2000) Simultaneous evanescent wave imaging of insulin vesicle membrane and cargo during a single exocytotic event. Curr Biol 10:1307-1310.

Wightman RM, Jankowski JA, Kennedy RT, Kawagoe KT, Schroeder TJ, Leszczyszyn DJ, Near JA, Diliberto EJ Jr, Viveros OH (1991) Temporally resolved catecholamine spikes correspond to single vesicle release from individual chromaffin cells. Proc Natl Acad Sci U S A 88:10754-10758.

Zhang X, Poo MM (2002) Localized synaptic potentiation by BDNF requires local protein synthesis in the developing axon. Neuron 36:675-688.

Zhu PC, Thureson-Klein A, Klein RL (1986) Exocytosis from large dense cored vesicles outside the active synaptic zones of terminals within the trigeminal subnucleus caudalis: a possible mechanism for neuropeptide release. Neuroscience 19:43-54. 